\title{
Electrophysiological Evidence on the Time Course of Semantic and Phonological Processes in Speech Production
}

\author{
Miranda van Turennout, Peter Hagoort, and Colin M. Brown \\ Max Planck Institute for Psycholinguistics
}

\begin{abstract}
The temporal properties of semantic and phonological processes in speech production were investigated in a new experimental paradigm using movement-related brain potentials. The main experimental task was picture naming. In addition, a 2-choice reaction go/no-go procedure was included, involving a semantic and a phonological categorization of the picture name. Lateralized readiness potentials (LRPs) were derived to test whether semantic and phonological information activated motor processes at separate moments in time. An LRP was only observed on no-go trials when the semantic (not the phonological) decision determined the response hand. Varying the position of the critical phoneme in the picture name did not affect the onset of the LRP but rather influenced when the LRP began to differ on go and no-go trials and allowed the duration of phonological encoding of a word to be estimated. These results provide electrophysiological evidence for early semantic activation and later phonological encoding.
\end{abstract}

Speaking is a central skill of the human species. An essential component of this complex human capacity is to transform a mental concept into a sequence of spoken sounds. If, for instance, people want to name an object in their environment, the visual recognition of the object allows them to activate an associated concept. This concept is used to retrieve from the mental lexicon all the information required for pronouncing the name of the object. The lexical information concerns semantic and syntactic specifications of the object name, as well as its sound pattern. The process of mapping a conceptual structure onto lexical representations is referred to as lexical access. To date, most speech production research has been dedicated to the study of lexical access.

At a general level, lexical access can be fractionated into semantic and phonological processing. It is generally acknowledged that these two are distinct and that they exploit different kinds of knowledge (Butterworth, 1989; Dell, 1986; Garrett, 1975, 1976, 1988; Kempen \& Huijbers, 1983; Levelt, 1989). There is less agreement, however, on the interplay over time between semantic activation and phonological encoding. Evidence on the time course of semantic activation and phonological encoding has come from analyzing word-order preferences (e.g., Bock, 1986), from speech error analyses (e.g., Dell, 1986), and from reaction time

Miranda van Turennout, Peter Hagoort, and Colin M. Brown, Max Planck Institute for Psycholinguistics, Nijmegen, The Netherlands.

This research was supported by the Max Planck Society, München, Germany. We are grateful to Michael Coles and Willem Levelt for valuable discussions of the data and useful comments on drafts of this article.

Correspondence concerning this article should be addressed to Miranda van Turennout, Max Planck Institute for Psycholinguistics, Wundtlaan 1, NL-6525 XD Nijmegen, The Netherlands. Electronic mail may be sent via Internet to m.v.turennout@mpi.nl. research (e.g., Levelt et al., 1991; Schriefers, Meyer, \& Levelt, 1990). In the present study, we introduce a new technique into the field of language production: the registration of event-related brain potentials (ERPs). One of the useful characteristics of ERPs is their millisecond-tomillisecond temporal resolution. They have been successfully used to study the nature and the temporal properties of several cognitive processes, such as language comprehension (e.g., Hagoort, Brown, \& Groothusen, 1993; Kutas \& Hillyard, 1980; Kutas \& Van Petten, 1988; Osterhout \& Holcomb, 1992), attention (e.g., Hillyard, Mangun, Woldorff, \& Luck, 1995; Hillyard \& Münte, 1984; Näätänen, 1990), memory (reviewed in Rugg, 1995), and perceptual-motor information transmission (e.g., Coles, 1989; De Jong, Wierda, Mulder, \& Mulder, 1988; Gratton, Coles, Sirevaag, Eriksen, \& Donchin, 1988; Miller, 1991). However, there is no report in the literature of ERP studies focusing on cognitive processes underlying speaking. ${ }^{1}$ The present study is the first that uses ERPs to measure the time course of semantic activation and phonological encoding in speech production.

\section{General Model of Speech Production}

The various cognitive processes involved in speaking are usually partitioned into three types (Bock, 1982; Dell, 1986; Garrett, 1975, 1988; Kempen, 1977; Kempen \& Hoenkamp, 1987; Levelt, 1989). The generation of an utterance starts with conceptualization. This process specifies the content of the utterance and generates a prelinguistic representation of the intended speech. The result is a conceptual structure that serves as input for formulation. In this process, the linguistic

\footnotetext{
1 There are some reports of ERP studies on speech production, but these studies focused on motor mechanisms underlying speaking (e.g., McAdam \& Whitaker, 1971; Grözinger, Kornhuber, \& Kriebel, 1977; Deecke, Engel, Lang, \& Kornhuber, 1986; Wohlert, 1993).
} 
representation that best matches the conceptual structure is retrieved from the mental lexicon. The formulation process involves grammatical and phonological encoding. During grammatical encoding, lexical items are selected on the basis of their meaning and syntactic specifications, and a syntactic frame of the utterance is generated. During phonological encoding, the sound form of the utterance is created: The word forms of the lexical items are retrieved, and the metrical structure and the intonation pattern of the utterance are specified. The final product of phonological encoding is a phonetic program that serves as input for articulation. The articulation process translates the phonetic program into an articulatory motor program and guides the execution of the motor commands. (See Levelt, 1989, for a detailed description of the cognitive processes involved in speaking.)

\section{Two-Stage Approaches to Lexical Access}

Lexical access is part of the formulation process and is assumed to proceed in two steps (Butterworth, 1980; Dell, 1986; Garrett, 1976; Kempen \& Huijbers, 1983; Levelt, 1983, 1989). In the first step, lemma retrieval, a set of lemmas is activated by the conceptual input. Lemmas are representations of the meaning and the syntactic characteristics of the lexical items (Kempen \& Huijbers, 1983; Levelt, 1989). They get activated if some of their semantic properties match the conceptual input. The activation of a lemma makes available the syntactic characteristics of the lexical item needed for grammatical encoding (such as word class and gender; see Kempen \& Huijbers, 1983; Levelt, 1989). After some time, the highest activated lemma is selected (for a computational model of lemma retrieval, see Roelofs, 1992). In the second step of lexical access, phonological encoding, the phonological form of the item is accessed, and a phonetic representation of the word is constructed (for models of phonological encoding, see Dell, 1986, 1988; ShattuckHuffnagel, 1979, 1983, 1987; see Meyer, 1992, for a discussion of different approaches to phonological encoding).

The distinctiveness of the semantic and phonological processing stages has been demonstrated by various kinds of behavioral data, including speech errors (e.g., Garrett, 1976), the tip-of-the-tongue phenomenon (see Brown, 1991, for an overview), and reaction time data (e.g., Levelt et al., 1991; Schriefers et al., 1990). Also, neuropsychological data provide evidence for two distinct stages (e.g., Butterworth, 1989; Howard \& Franklin, 1989; Kay \& Ellis, 1987). In addition, recent brain imaging research suggests the involvement of different brain areas in semantic and phonological processes (e.g., Petersen \& Fiez, 1993).

Although there is agreement in the literature on the distinction between a semantic and a phonological processing stage, the temporal properties of the two stages are still a matter of debate. Modular theories claim that the stages of semantic and phonological activation are strictly separated in time (e.g., Garrett, 1975; Levelt, 1989; Levelt et al., 1991). This means that lemma selection does not only precede phonological encoding, but has to be completed before phonological encoding can start. Therefore, the phonological form will only be constructed for the selected lemma. According to this view, then, phonological activation cannot affect lemma selection. A contrasting view is held by interactive models (e.g., Dell, 1986; Dell \& Reich, 1981; Harley, 1984; Stemberger, 1985). Although these models do not dispute that lexical items are initially activated on the basis of their meaning, they allow for a continuous spread of activation between the stages of semantic and phonological activation. All semantic activation feeds forward into the phonological processing stage, and activation spreads back from the phonological level to the semantic level. Furthermore, word-form encoding is not restricted to one lemma, but can occur for several activated lemmas. Therefore, in interactive models, the final selection of a particular lexical item is dependent on the activational dynamics at both the lemma and the lexeme level.

Evidence for the modular view of lexical access initially came from analyses of speech-error data. These analyses showed, for instance, that a distinction can be made between meaning-based and form-based errors. These two error types were argued to occur independently of each other, suggesting that they originate from two separate processing levels (e.g., Fromkin, 1971; Garrett, 1975, 1988; see Butterworth, 1989, for a review).

More recently, evidence for a modular account of lexical access has been provided by reaction time studies. In a study using a picture-naming task, Schriefers et al. (1990) asked participants to name a picture while hearing an interfering word. The interfering word could be phonologically or semantically related to the picture name and was presented at different moments in time. The results of this study show that semantically related words interfere with picture naming in an early phase of the naming process, whereas phonologically related words affect the naming process only in a later phase. In another reaction time study, using a different experimental paradigm, Levelt et al. (1991) found no evidence for phonological activation of semantic alternatives of the target word. Only phonological activation of the target lemma was observed. This indicates that a lemma has to be selected before its lexeme is activated. Although these results are interpreted as providing evidence for a modular approach, this interpretation is controversial and remains a matter of dispute (see Dell \& O'Seaghdha, 1991, 1992; Harley, 1993).

The modular view of lexical access has also been challenged on the basis of speech-error analyses (e.g., Dell \& Reich, 1981; Martin, Gagnon, Schwartz, Dell, \& Saffran, 1995; Martin, Weisberg, \& Saffran, 1989). Speech-error analyses show that there is a tendency for sound errors to result in real words, which has been called the lexical bias effect (cf. Baars, Motley, \& MacKay, 1975). Related to this is the observation that semantic errors tend to occur between words that share phonological features (e.g., rat is said instead of cat). These errors are usually referred to as mixed errors. The probability of their occurrence appears to be higher than would be predicted from the independent contributions of semantic and phonological similarity. The lexical bias effect and the occurrence of mixed errors suggest that semantic and phonological information interactively affect lexical selection. In a serial approach to lexical 
access, it is hard to account for mixed errors and the lexical bias effect, because activation at the word-form level is not allowed to influence lexical selection. Interactive models, on the other hand, predict the occurrence of these error types. In these models, activation at the word-form level spreads back into the lemma level, which allows semantic and phonological processes to interact.

A major reason for the continuing debate lies in the fact that the claims of the competing models with respect to the time course of the ongoing processes have become more and more fine-grained. As a consequence, a definitive test by means of reaction time measures alone is increasingly unlikely. To increase our insight into the on-line process of lexical access, we need to incorporate new research techniques that can-in principle-provide a more detailed picture of the temporal dynamics of lexical access in production.

The goal of the present study is twofold. First, we want to validate a new experimental paradigm that uses ERPs to study the temporal properties of semantic and phonological processes in speech production. Second, we want to obtain converging evidence regarding the temporal separation between semantic and phonological processing stages. This study does not provide conclusive evidence for either a modular or an interactive approach, but is a first attempt to create new possibilities for testing this and other central issues in language production research. The ERP component we use is the lateralized readiness potential. First we describe the characteristics of this ERP measure. Then we explain how we used it in the present study and describe the experimental paradigm.

\section{The Lateralized Readiness Potential}

The lateralized readiness potential (LRP) is derived from the readiness potential, or Bereitschaftspotential. The readiness potential was first described by Kornhuber and Deecke (1965). It is a slow, negative-going potential that starts to develop some time prior to the execution of a voluntary hand movement and reaches its maximum just after movement onset. The readiness potential is largest in amplitude at scalp sites overlying the motor cortex contralateral to the responding hand (cf. Kutas \& Donchin, 1974, 1977, 1980; Vaughan, Costa, \& Ritter, 1968). Several researchers showed that if, in a choice reaction time task, information about the side of the response is given in advance, the readiness potential starts to lateralize in the period between the appearance of the informative signal and the appearance of the signal to respond (Kutas \& Donchin, 1980; Rohrbaugh, Syndulko, \& Lindsley, 1976). Therefore, Kutas and Donchin (1980) suggested that the lateralization of the readiness potential can be used as an index for specific response preparation. This idea has been elaborated by numerous researchers (Coles, Gratton, \& Donchin, 1988; De Jong et al., 1988; Gratton et al., 1988; Smid, Mulder, \& Mulder, 1987) and has led to what is now known as the LRP, which has been shown to be a specific index for response preparation. The LRP can be derived as follows: ${ }^{2}$

$$
\mathrm{LRP}=\text { right hand }\left(\mathrm{C} 3^{\prime}-\mathrm{C} 4^{\prime}\right)-\text { left hand }\left(\mathrm{C3}^{\prime}-\mathrm{C} 4^{\prime}\right) .
$$

First, on each trial a waveform representing the difference between potentials recorded from electrode sites $\mathrm{C}^{\prime}$ and $\mathrm{C}^{\prime}{ }^{\prime}$ is obtained. The electrode sites $\mathrm{C}^{\prime}$ and $\mathrm{C4}^{\prime}$ are located above the left and the right motor cortices, where the readiness potential during hand movements has been found to be largest in previous research (Kutas \& Donchin, 1980). Second, these waveforms are averaged separately for trials in which the left hand is cued and for trials in which the right hand is cued. Third, the average waveform obtained for the left-hand trials is subtracted from the average waveform obtained for right-hand trials. This subtraction cancels out lateralized potentials that are not specifically related to response preparation. The resulting LRP reflects the average amount of lateralization occurring as a result of response preparation (see, e.g., Coles, 1989; De Jong et al., 1988). The LRP has a negative polarity if response preparation for the cued response hand occurs and has a positive polarity if preparation for the incorrect response occurs.

The LRP has been used in a number of elegant studies to assess aspects of human information processing (e.g., Coles, 1989; Coles et al., 1988; De Jong et al., 1988; Gratton et al., 1988; Miller \& Hackley, 1992; Osman, Bashore, Coles, Donchin, \& Meyer, 1992; Smid, Mulder, Mulder, \& Brands, 1992). In particular, the LRP has been used to detect the transmission of partial information between perceptual and motor processes. The results of these studies have established that an LRP can develop on the basis of partial stimulus evaluation and in the absence of an overt response. This indicates that partial information about a stimulus can be used to select and prepare responses before the stimulus has been fully identified. Whether partial information is used to select responses can be influenced by the particular task conditions. For example, it has been shown that in some experimental conditions, participants are able to strategically control the transmission of partial information (e.g., Gratton, Coles, \& Donchin, 1992; Smid et al., 1992; see Coles, Smid, Scheffers, \& Otten, 1995, for an overview). This means that partial information might be available, but not used for response preparation. As a consequence, the development of an LRP does not indicate precisely when information becomes available, but indicates that information is used to activate responses. This implies that relevant partial information is available at least at LRP onset but that it may have been available earlier as well.

When these studies are considered together, we can conclude that the LRP is a real-time measure of response preparation and that it can be used to detect the relative moments in time at which different kinds of information influence response preparation. The onset of the LRP can be interpreted as an estimate for the moment at which information was used for response preparation. Let us now turn to the use of the LRP in the study of semantic and phonological processing in speech production.

\footnotetext{
${ }^{2}$ This measure is equivalent to what De Jong et al. (1988) called the corrected motor asymmetry. This derivation of the LRP is also equivalent to that of Coles (1989) and Gratton et al. (1988)-left hand $\left(\mathrm{C} 4^{\prime}-\mathrm{C} 3^{\prime}\right)+$ right hand $\left(\mathrm{C} 3^{\prime}-\mathrm{C} 4^{\prime}\right) / 2$ - except that it has twice the amplitude.
} 
The evidence for the transmission of partial information on the one hand, and the evidence for the distinctiveness of semantic and phonological processing on the other hand, make it plausible to assume that the output of the semantic and phonological processing stages can be transmitted separately to the response processes. We hypothesize that if semantic activation precedes phonological encoding in time, the results of the semantic-activation process will be transmitted to the response system earlier than the results of the phonological-encoding process. This implies that if a response is related to a combined semantic and phonological stimulus evaluation, response preparation will first be based on semantic information alone (partial evaluation), followed by the response preparation based on both semantic and phonological information (complete evaluation).

To use the LRP in the study of speech production, an experimental situation is required in which semantic and phonological processing during speech production are related to response preparation. The response conditions have to be chosen in such a way that the influence of semantic information on response preparation can be distinguished from the influence of phonological information on response preparation. A procedure meeting this requirement is the two-choice reaction go/no-go paradigm (Miller \& Hackley, 1992; Osman et al., 1992; Smid et al., 1992), which is the procedure we used here.

\section{Experimental Paradigm}

Picture naming is an experimental task that is often used to investigate the time course of speech production (reviewed in Glaser, 1992). In the present study, we used a picture-naming task to initiate the speech process. On 50\% of the trials, a frame appeared around the picture $150 \mathrm{~ms}$ after picture onset. The frame served as a cue to perform a secondary task before picture naming.

The secondary task was the critical experimental task and involved a two-choice go/no-go task. Participants were asked to classify the picture along a semantic dimension and along a phonological dimension. Depending on the outcome of the semantic and phonological classifications, a left-hand response, a right-hand response, or neither response was given. The semantic classification involved an animateinanimate decision. There is a sizable literature on the mechanisms underlying picture categorization in relation to picture naming and word categorization. An extensive review of these studies is given in Glaser's (1992) article. On the basis of this literature, we assume that the animateinanimate categorization taps into the stage of semantic activation.

The phonological classification involved a word-final phoneme decision (Experiment 1 and Experiment 2) or a word-initial phoneme decision (Experiment 3). We assume that the phoneme decision task taps into the stage of phonological encoding. To make this decision, the phonological segments of the word have to be available, which requires that the segments of the word have been spelled out. A study by Wheeldon and Levelt (1995) showed that phoneme monitoring in a language production task is sensitive to the time course of phonological encoding, which supports the assumption that the phoneme decision task taps into a phonological processing stage.

In Experiment 1, we attempted to detect response preparation based on semantic information alone. In this experiment, the semantic classification determined the response side (e.g., in the case of an animal, a right-hand response had to be made, and in the case of an object, a left-hand response had to be made). The phonological classification determined whether the response should be executed or not (e.g., a response had to be executed if the picture name ended with the phoneme $/ \mathrm{n} /$, but it had to be withheld if the picture name ended with the phoneme $/ \mathrm{s}$ ) .

The logic behind the paradigm is as follows. At the moment of appearance of the task cue $(150 \mathrm{~ms}$ after picture onset), participants are in an early phase of the naming process. We assume that if, in speech production, semantic activation precedes phonological encoding, semantic information about the picture will be available earlier than phonological information about the picture name. This assumption is illustrated in Figure 1. In this figure, period $a-b$ represents the period during which semantic information becomes available for response preparation, and period $c-d$ represents the period during which information about the word form becomes available. The critical test involves the presence or absence of an LRP on no-go trials. On the basis of the previously described LRP studies, we assume that information is transmitted to the response system as soon as it becomes available. With reference to Figure 1 , this means that the preparation of the correct response hand can start during period $a-b$, whereas the go/no-go distinction can be made only during period $c-d$. Therefore, in the case that semantic information is available earlier than phonological information, we expect an LRP to develop on both go and

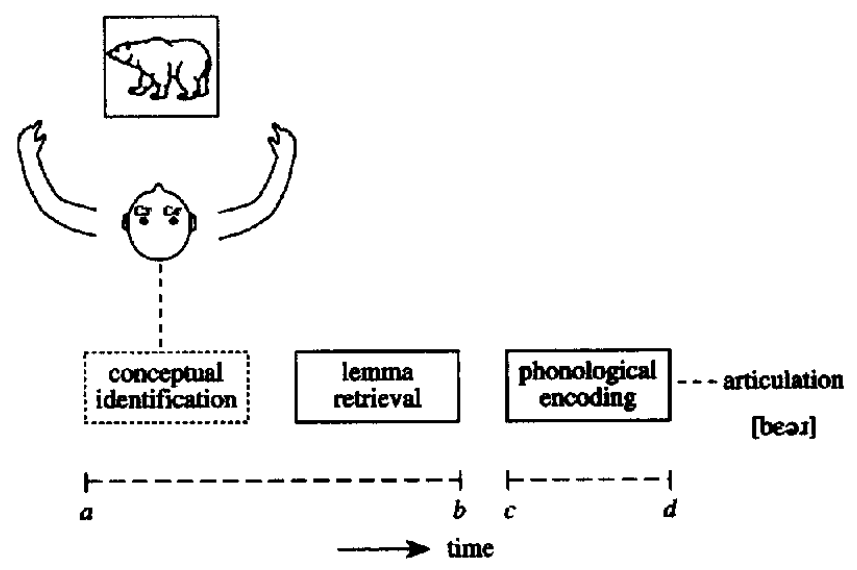

Figure 1. Processing stages in picture naming using the lateralized readiness potential paradigm. Semantic information about the picture becomes available for response preparation during conceptual identification and lemma retrieval. Phonological information about the picture name becomes available for response preparation during phonological encoding. Under the hypothesis that conceptual identification and lemma retrieval precede phonological encoding, response preparation is first based on semantic information (period $a-b$ ), and phonological information affects response preparation at a later moment (period $c-d$ ). $\mathrm{C3}^{\prime}$ and $\mathrm{C4}^{\prime}$ are electrode sites. 
no-go trials at about the same latency. After some time, response preparation on no-go trials will decrease because of the completion of the phonological decision, and the LRP will return to the baseline, without producing an ERP profile that is associated with an overt response.

To validate the logic behind the paradigm, a second experiment was carried out. In this experiment the task instruction was reversed. That is, the result of the phonological analysis determined the response hand, and the result of the semantic analysis determined the go/no-go decision. This means that selective response preparation could start only if the phonological analysis had been completed. Under the hypothesis that the semantic analysis is completed before the phonological analysis, we expected that the go/no-go decision could be made before information about the response hand became available (see Figure 1). Therefore, the presence of an LRP was expected only for go trials.

In a third experiment, we used the same task instruction as in Experiment 1, with one difference: The phonological go/no-go decision was based on the word-initial phoneme instead of the word-final phoneme of the target word. Apart from validating the pattern of results obtained in Experiment 1 , this manipulation allowed us to determine whether the LRP is sensitive to the temporal properties of phonological encoding. If word-initial phonological information is available earlier than word-final phonological information, the go/no-go distinction could be made faster in Experiment 3 than in Experiment 1. As a result, in Experiment 3 the go and no-go LRPs should start to diverge from each other at an earlier point than in Experiment 1.

In addition to recording LRPs, the electroencephalogram (EEG) was recorded from midline frontal $(\mathrm{Fz})$, central $(\mathrm{Cz})$, and parietal $(\mathrm{Pz})$ sites, to validate the LRP measurements. Because the results were as expected in all three experiments, we present a composite report of the midline data in the Discussion section of Experiment 3.

\section{Experiment 1}

\section{Method}

\section{Participants}

Sixteen undergraduate students ( 2 male) between 20 and 25 years of age from the participant pool of the Max Planck Institute for Psycholinguistics participated in the experiment; all were native speakers of Dutch. They were all right-handed according to their response on an abridged and adapted Dutch version of the Oldfield Handedness Inventory (Oldfield, 1971). Except for 1 participant, no left-handedness occurred among the direct relatives of the participants. All participants had normal or corrected-to-normal vision. None of them had any neurological impairment or had experienced any neurological trauma according to their responses on a questionnaire. They were paid for their participation.

\section{Materials}

A set of pictures was selected according to the following criteria. The first criterion was that the pictures had to be unambiguous. That is, they had to be labeled in an identical way by most of the participants in a naming task. This should guarantee that for the selected pictures, the intended lexical items were retrieved by the participants. The second criterion was that the selected set of pictures had to be fairly homogeneous with respect to perceptual processing time. That is, times to recognize a picture as depicting a particular object or animal should have been roughly the same for all pictures. Because the present study focuses on the moments at which semantic and phonological information become available during the naming process, we had to minimize the variability in recognition times for the individual pictures by selecting as homogeneous a set as possible.

To establish a set of pictures meeting the two criteria, we pretested a large set of pictures in a picture-naming experiment and a picture-recognition experiment. The selection of the set of experimental pictures was based on the results of these two pretests.

Picture-naming pretest. In this pretest, 57 pictures of animals and 98 pictures of objects were successively presented for $600 \mathrm{~ms}$ each, with an intertrial interval of $2,400 \mathrm{~ms}$. Twenty participants took part in the pretest and were paid for their participation. They were instructed to name the pictures as quickly as possible. Four random presentation orders were constructed and balanced among the 20 participants. Pictures were presented on a NEC/Multisync $3 \mathrm{D}$ computer screen. Naming responses were recorded with a Sony 300 ES digital recorder. Naming latencies were measured from picture onset by a voice key.

A picture was said to elicit a consistent naming response if it was given an identical name by at least $80 \%$ of the participants. Thirty-five pictures of animals and $\mathbf{8 6}$ pictures of objects met this criterion. These pictures were used as target pictures in the picture-recognition pretest.

Picture-recognition pretest. The pretest was administered to 14 paid participants who did not take part in the previous test. Pictures were presented in the same way as in the picture-naming pretest. To determine the recognition times for these pictures, participants were given an old-new judgment task. In this task, participants were initially presented with a set of 50 filler pictures, which they were asked to remember. Subsequently, they were presented with another series of pictures, consisting of the $\mathbf{5 0}$ filler pictures shown in the initial phase and 121 new pictures. The pictures were presented in a random order. The participants' task was to indicate whether the picture was old (i.e., presented before) or new, by pressing one of two buttons. The new button was assigned to the participants' dominant hand. Response latencies were measured from picture onset. The critical pictures were the nonrepeated pictures, which had to be indicated as new. The assumption was that to give a correct new response, a picture had to be recognized, but did not need to be lexicalized. Therefore, differences in reaction times would reflect differences in the duration of perceptual identification. Mean reaction times and error percentages were calculated for the 121 target pictures. The overall error percentage was $2.4 \%$.

The resulting set of pictures. A set of 32 pictures was selected for the main experiments. The selection of the pictures was based on the results of the pretests. To minimize the differences in perceptual features between the animal and object pictures, we were careful to select pictures that were as similar as possible in terms of curves, straight lines, edges, and so forth. The mean naming latencies and the mean recognition times of the selected items are listed in Appendix A. In addition, 16 pictures were selected as filler items. In the complete experimental picture set, 24 pictures depicted animals, and the remaining 24 pictures represented objects. The names of these pictures included four different word-final phonemes, namely $/ N, / s /, / n /$ and $/ r /$. Each of these word-final phonemes was represented equally often in the picture set. The combination of the two semantic categories and the four phonological categories resulted in the following eight sets of 
pictures: animal, word-final $/ /$ (e.g., uil [owl]); animal, word-final /s/ (e.g., muis [mouse]); animal, word-final /r/ (e.g., beer [bear]); animal word-final $/ \mathrm{n} /$ (e.g., spin [spider]); object, word-final $/ /$ (e.g., bal [ball]); object, word-final /s/ (e.g., muts [cap]); abject, word-final /r/ (e.g., deur [door]); object, word-final /n/ (e.g., schoen [shoe]). In addition, a set of practice pictures was selected. This set consisted of 8 animals and 8 objects. The picture names had the phoneme $/ \mathrm{p} /$ or the phoneme $/ /$ at word-final position.

\section{Procedure}

Participants were tested individually. They were seated in a soundproof booth in front of a computer screen. A trial started with the presentation of a fixation point in the middle of the screen. After $750 \mathrm{~ms}$, the fixation point disappeared, and the screen stayed blank for $750 \mathrm{~ms}$. Then a picture was presented for $2,500 \mathrm{~ms}$. Participants were instructed to name the picture as quickly as possible. At 150 $\mathrm{ms}$ after picture onset, a frame was superimposed around the picture in half of the trials. The appearance of the frame signaled that the semantic-phonological judgment task had to be carried out before picture naming. Participants were instructed to rest their arms and hands on the elbow rest of the chair and to hold their index fingers on the left and the right response buttons. For go trials, participants responded by pressing one of the two buttons as quickly as possible. For no-go trials, participants did not press any of the buttons. The frame remained on the screen for $1,500 \mathrm{~ms}$, during which a response had to be made. Participants were instructed not to speak during this period. After the frame had disappeared, participants named the picture. Participants were asked not to blink or to move their eyes during the period in which the picture was on the screen.

At the beginning of a session, the practice set was presented to familiarize participants with the task. Practice trials were presented until the participants performed the task accurately. Electrodes for measuring electrophysiological activity were applied after the training session. Before the experimental blocks were presented, participants were given a booklet containing all experimental pictures and their names. They were asked to carefully look at the pictures and to use the given names in the experiment. When a participant indicated that he or she had looked at all pictures and their names, the actual experiment started.

The actual experiment consisted of two series of six experimental blocks. One series contained all word-final $/ /$ and word-final $/ \mathrm{s} /$ items, and the other series contained all word-final $/ n /$ and word-final $/ \mathrm{r} /$ items. The order in which the two series were presented was balanced across participants. Each of the series started with a practice block containing all pictures that would be presented during that series. In each of the series, pictures were repeated 10 times. Test pictures were presented 6 times in critical judgment trials and 4 times in naming trials. Filler pictures were presented 3 times in filler judgment trials and 7 times in naming trials. As a result, $50 \%$ of the trials were naming-only trials, and $50 \%$ of the trials had the judgment task in addition.

A block of experimental trials was composed as follows. There were 16 critical judgment trials in which the test pictures were presented. In addition, there were 4 filler judgment trials and 20 naming trials in which test pictures and filler pictures were presented. The items were presented in a pseudorandomized order: Repeated items were always separated by at least eight other items, and there were never more than 3 successive naming trials or more than 3 successive judgment trials. Each block lasted 4 min, and there was a short break between the blocks. Between the first series of six blocks and the second series of six blocks, participants were given a 10-15 min break.

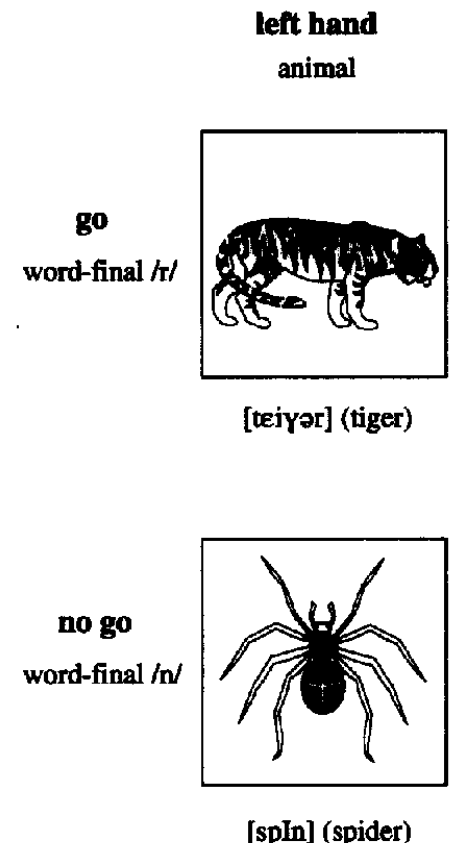
right hand
object

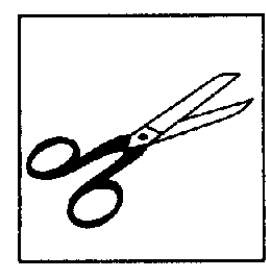

[sxa:r] (scissors)

[spln] (spider)

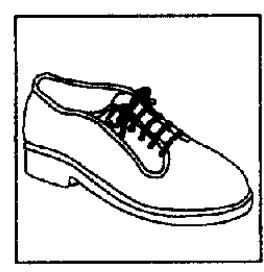

[sxu:n] (shoe)

Figure 2. Examples of the pictures used in the semanticphonological categorization task in Experiment 1. In the figure, the Dutch picture names (in the international phonetic alphabet [International Phonetic Association, 1967]) are shown below the pictures. The four pictures depicted here represent separate trials for the four experimental conditions. An animal cues a left-hand response, and an object cues a right-hand response. The response has to be executed if the picture name ends with an $/ \mathrm{r} /$ (go trials) but is withheld if it ends with an $/ \mathrm{n} /$ (no-go trials).

Examples of the stimuli are shown in Figure 2. In these, an animal cues a left-hand response and an object cues a right-hand response. A response has to be executed if the picture name ends with the phoneme $/ r$ / but is withheld if the picture name ends with an $/ n /$. To control for material-specific effects, four experimental versions were constructed. The versions were presented to separate groups of 4 participants. Across versions, the assignment of the four response types (left hand go, left hand no-go, right hand go, right hand no-go) to the four picture sets in each of the two blocks was rotated in such a way that each picture contributed equally to each of the four response types. For example, the picture of a tiger would cue a right-hand response in Version 1, a left-hand response in Version 2, and no response in Version 3 and Version 4.

\section{Apparatus}

The pictures were presented in the center of a high-resolution NEC/Multisync 3D computer screen, in white on a black background. The presentation of the stimuli and the acquisition of the reaction time data were controlled by NESU, a system developed at the Max Planck Institute for Psycholinguistics, using a Hermac AT computer. Naming latencies were measured from picture onset by a Sennheiser voice key. Push buttons were attached to the left and the right arm of the chair. Hand responses were made by pressing either the button on the left side or the button on the right side of the chair with an index finger. Push-button latencies were measured from frame onset. The time-out period (the moment in time after which responses were registered as missing) was set at $2,500 \mathrm{~ms}$ for the naming response and at $1,500 \mathrm{~ms}$ for the push-button response. 
Participants' naming responses were recorded by a Sony 300 ES DAT recorder.

\section{Electrophysiological Recordings}

The EEG was recorded monopolarly from midline frontal (Fz), central $(\mathrm{Cz})$, and parietal $(\mathrm{Pz})$ sites as defined by the international 10-20 system (Jasper, 1958). These electrodes were referenced to the left mastoid. The difference in activity between $\mathrm{C3}^{\prime}$ and $\mathrm{C4}^{\prime}$ (approximately $3.5 \mathrm{~cm}$ lateral and $1 \mathrm{~cm}$ anterior to $\mathrm{Cz}$ ) was recorded with a bipolar montage of the two electrodes. A ground electrode was placed on the forehead. Vertical and horizontal eye movements were recorded bipolarly by electrodes placed above and below the right eye and external to the outer canthus of each eye. Bipolar recordings of the electromyogram (EMG) were made by placing pairs of electrodes above the responding muscles of each arm ( $M$. flexor digitorum superficialis and the $M$. flexor digitorum profundus). For all recordings, Beckmann biopotential $\mathrm{Ag} / \mathrm{AgCl}$ electrodes were used. Electrode impedance was kept below $3 \mathrm{k} \Omega$ for the EEG recording, below $10 \mathrm{k} \Omega$ for the electro-oculogram (EOG) recording, and below $20 \mathrm{k} \Omega$ for the EMG recording. The EEG, EOG, and EMG signals were amplified by Nihon Kohden AB-601G bioelectric amplifiers and filtered with a high-frequency cutoff point of $30 \mathrm{~Hz}$ for the EEG and EOG, and a high-frequency cutoff point of $100 \mathrm{~Hz}$ for the EMG. A time constant of $8 \mathrm{~s}$ was used. The signals were digitized on-line with a sampling frequency of $200 \mathrm{~Hz}$. Sampling started $200 \mathrm{~ms}$ before picture onset on a critical trial, with a total sampling epoch of 2,700 ms. The EMG signal was rectified off-line.

\section{Data Analysis}

Data from critical trials were analyzed as described below. Filler trials were not further analyzed.

Overt responses. First, the naming data and the push-button data were inspected for errors. A trial was classified as erroneous if the following occurred: (a) Naming started before the button press was given or started earlier than $1,500 \mathrm{~ms}$ after frame onset. These trials were removed to avoid articulatory artifacts in the EEG signal. (b) The picture was named incorrectly. (c) An incorrect hand response was given.

Second, each trial was visually inspected for the occurrence of EMG activity. From other studies (e.g., Coles, Gratton, Bashore, Eriksen, \& Donchin, 1985; Eriksen, Coles, Morris, \& O'Hara, 1985), it is known that response activation can occur without a response being executed. In trials where only one response is given, response activation can be concurrently present in both EMG channels. To make sure that the development of the LRP would not be biased by trials in which the incorrect response was activated earlier than or simultaneously with the correct response, all go trials in which EMG activity was detected in the incorrect channel were classified as error trials. In no-go trials, the presence of EMG activity could have been the result of erroneous or incomplete go/no-go analyses. To avoid the possibility that the presence of an LRP on no-go trials could be attributed to incomplete or incorrect go/no-go decisions, all no-go trials in which EMG activity occurred were classified as error trials. All error trials were eliminated from the data set.

Event-related potentials. All single trial waveforms containing eye movement artifacts, amplifier blocking, or electrode drifting, in the time window from $200 \mathrm{~ms}$ before picture onset to $1,500 \mathrm{~ms}$ after picture onset, were removed from the data set. From each single trial waveform, the average voltage in the 200 -ms period preceding picture onset was subtracted.
LRPs were derived separately for the go and no-go conditions. To test for the presence of an LRP and to estimate its onset, analyses were performed at 50 -ms intervals, starting at frame onset and continuing in sequential steps of $10 \mathrm{~ms}$ (e.g., $150-200 \mathrm{~ms}$, $160-210 \mathrm{~ms}$, etc.). For each window a one-tailed $t$ test with a $95 \%$ confidence interval was performed to test whether the mean voltage within the window exceeded the mean voltage within the baseline interval. An LRP was defined to be present if five or more consecutive windows resulted in a significant $t$ value. The onset of the first of these consecutive significant windows determined the LRP onset latency.

To determine the point of divergence between the go and no-go LRPs, the average voltage at each individual time point of the no-go waveform was subtracted from the average voltage at the corresponding time points of the go waveform. One-tailed $t$ tests were performed to test whether the mean go/no-go difference scores differed significantly from zero; the $t$ tests were performed with the same procedure as described for the individual LRP waveforms. The point of divergence was defined as the beginning of the earliest of five or more consecutive time windows that resulted in significant $t$ values.

To date, all of the published work on language and ERPs has been based on subject analyses. Item analyses have not been incorporated in the analytic procedures for ERP data, and such analyses were not performed on the current data set.

\section{Results}

\section{Overt Responses}

The mean push-button latency, measured from frame onset, for the correct go trials was $818 \mathrm{~ms}(S D=255)$; mean response latencies for animals and objects were $799 \mathrm{~ms}$ $(S D=268)$ and $838 \mathrm{~ms}(S D=249)$, respectively. The mean error rate for the go trials was $4.7 \%$. For the no-go trials, the mean error rate was $2.5 \%$. These errors included all trials on which EMG errors, as specified above, were detected. Because the error rates were small, they were not further analyzed.

The mean naming latency for the experimental pictures in the naming-only trials was $762 \mathrm{~ms}(S D=152)$, measured from picture onset.

\section{Lateralized Readiness Potentials}

In total, $19 \%$ of the trials were rejected because of errors and EEG artifacts. The rejected trials were equally distributed across conditions and participants. Per participant, the minimum number of trials left for averaging was 35 per condition.

Figure 3 presents the averaged LRP waveforms for the go trials and the no-go trials. ${ }^{3}$ This figure shows that a negative LRP developed on both go trials and no-go trials. Thus, on both go and no-go trials a greater negative potential was observed contralateral to the cued response hand. This enhanced negativity indicates the presence of preparation for the cued response hand. The go and the no-go LRPs started

\footnotetext{
${ }^{3}$ For presentation purposes, the waveforms in this and all other figures have been low-pass filtered (cf. Ruchkin \& Glaser, 1978) using a 50-ms time frame. The unfiltered data were used in all statistical analyses.
} 


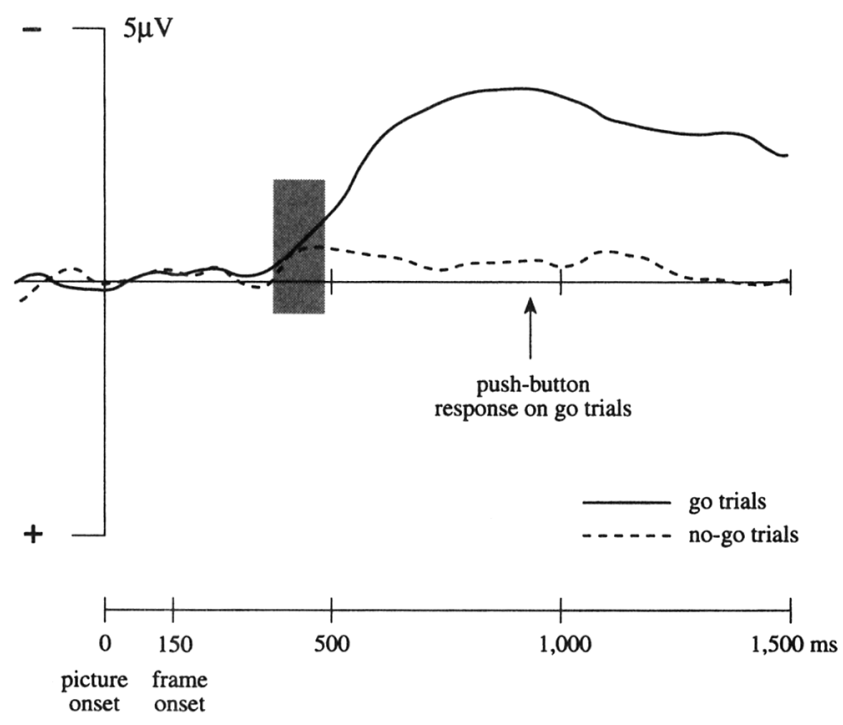

Figure 3. Grand average ( $N=16$ participants) lateralized readiness potentials (LRPs) on go and no-go trials of Experiment 1. The semantic decision determined response hand; the word-final phoneme decision determined whether a trial was a go or a no-go trial. Significant lateralization of the readiness potential was obtained both on go and on no-go trials. The shaded area shows the time interval in which the go and the no-go LRPs were significantly different from the baseline but not from each other.

to develop at approximately the same moment. On go trials, the LRP started to deviate significantly from zero at $370 \mathrm{~ms}$ after picture onset, $t(15)=-1.89, S D=0.95, p=.05$, which corresponds to $220 \mathrm{~ms}$ after frame onset. On no-go trials the LRP became significant at $380 \mathrm{~ms}$ after picture onset, $t(15)=-2.09, S D=0.90, p<.05$, which corresponds to $230 \mathrm{~ms}$ after frame onset. The LRP kept on developing on go trials, reaching its maximum value around $840 \mathrm{~ms}$ after picture onset. The no-go LRP slowly returned to the baseline after its initial development. At $590 \mathrm{~ms}$ after picture onset, the $t$ value for the mean LRP amplitude was no longer significant, $t(15)=-1.68, S D=0.81, p=.1$. To provide information about the variation among participants, plots of individual go and no-go LRP waveforms are shown in Figure 4. In this figure, it can be seen that for the majority of participants a lateralization of the readiness potential was obtained on both go and no-go trials.

The difference between the go and the no-go waveforms became significant $490 \mathrm{~ms}$ after picture onset, $t(15)=$ $-1.99, S D=1.26, p<.05$. This means that after their initial onset, the go and the no-go LRPs developed at the same rate for about $120 \mathrm{~ms}$.

\section{Discussion}

The main findings of Experiment 1 concern the development of the LRP on no-go trials. In parallel with the development of an LRP on go trials, an LRP developed on no-go trials for a short period of time. This means that the cued response hand was activated even when the phonological evaluation cued no response. The onset latency of the LRP was about the same in go and no-go trials, indicating that response preparation started in the same time range on both kinds of trials. This suggests that semantic information was used to activate the response hand before phonological information could be used to make the go/no-go distinction. The go and no-go LRPs developed at the same rate for 120 $\mathrm{ms}$, after which they started to diverge. Thus, after $120 \mathrm{~ms}$ the phonologically based go/no-go distinction influenced the development of the LRP. On go trials, the LRP kept on growing, but on no-go trials the LRP returned to the baseline without any EMG activity being produced.

The LRP results obtained in Experiment 1 suggest a temporal advantage of semantic information over phonological information. The early available semantic information serves as partial information, and therefore response preparation can start before sufficient phonological information is available to complete the go/no-go analysis. To validate this interpretation, Experiment 2 was carried out. In this experiment, we reversed the assignment of the semantic and phonological evaluation to the left-right and the go/no-go dimensions. This manipulation allowed us to determine whether the no-go LRP observed in Experiment 1 reflected a temporal difference between semantic and phonological processing, or whether it was due to mechanisms that are independent of the time course of the two distinct types of processes.

\section{Experiment 2}

Just as in the first experiment, target pictures were presented to participants, and in addition to naming the picture, participants had to perform a two-choice reaction go/no-go task on $50 \%$ of the trials. However, in Experiment 2 , the assignment of the semantic and phonological dimensions to the go/no-go and response hand decisions was the mirror image of that in Experiment 1: In Experiment 2, the go/no-go distinction was determined by the animateinanimate decision, and the response hand was determined by the word-final phoneme decision. Assuming that semantic information precedes phonological information, no selective response activation should be present on no-go trials in Experiment 2, because the go/no-go decision on the basis of semantic information can be completed before the response hand can be prepared on the basis of phonological information.

\section{Method}

Sixteen undergraduate students ( 2 male) between 20 and 26 years of age from the participant pool of the Max Planck Institute for Psycholinguistics took part in the experiment and were paid for their participation. Nine of them had already participated in Experiment 1. They were all native speakers of Dutch and had normal or corrected-to-normal vision. All participants were righthanded according to their response on an abridged adapted Dutch version of the Oldfield Handedness Inventory (Oldfield, 1971). No left-handedness occurred among the direct relatives of the participants. None of the participants had any neurological impairment or had experienced any neurological trauma.

Materials, procedure, apparatus, electrophysiological recordings, and data analysis were the same as those described for Experiment 1. 

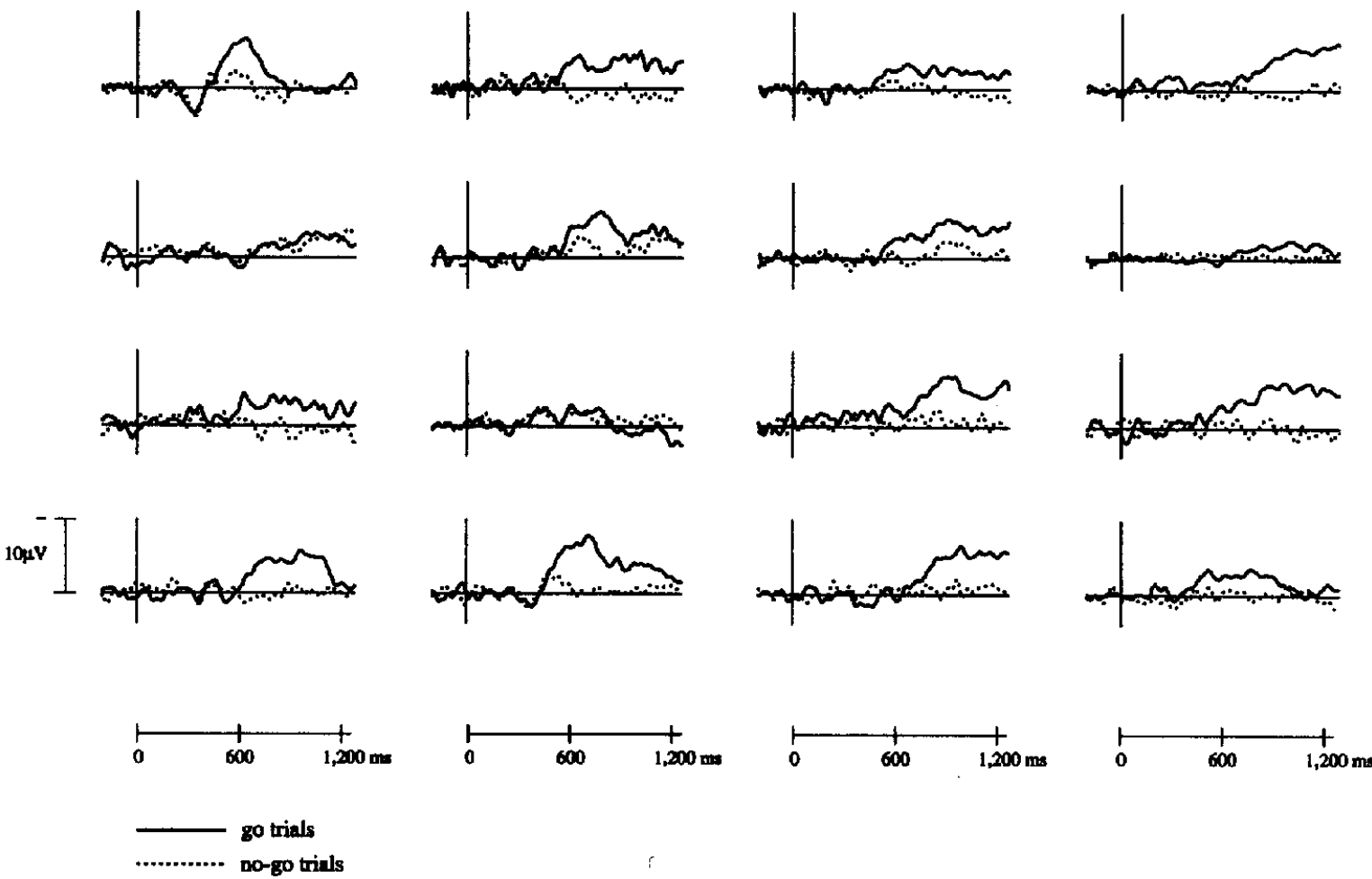

Figure 4. Lateralized readiness potentials on go and no-go trials for each of the participants in Experiment 1. The first nine plots, depicted from left to right, show data from the individuals who participated in both Experiments 1 and 2.

\section{Results}

\section{Overt Responses}

The mean response time for the correct go trials was 816 $\mathrm{ms}(S D=230)$ after frame onset; mean response latencies for the word-final phonemes $/ \mathrm{n} /, / \mathrm{r} /, / /$, and $/ \mathrm{s} /$ were $824 \mathrm{~ms}$ $(S D=246), 811 \mathrm{~ms}(S D=226), 815 \mathrm{~ms}(S D=234)$, and $816 \mathrm{~ms}(S D=240)$, respectively. The error rate for the go trials was $4.2 \%$. For the no-go trials, the error rate was $2.2 \%$. As in Experiment 1, the error rates were not further analyzed.

The mean naming latency for the experimental pictures in the naming-only trials was $719 \mathrm{~ms}$, measured from picture onset.

\section{Lateralized Readiness Potentials}

The overall rejection rate was $18 \%$. The rejected trials included all trials on which response errors or EEG artifacts were observed. The rejected trials were equally distributed across the conditions and participants. Per participant, the minimum number of trials left for averaging was 35 per condition.

The averaged LRP waveforms for go trials and no-go trials are presented in Figure 5. In this figure, we can see a negative LRP developing on go trials. The go waveform started to deviate from zero $410 \mathrm{~ms}$ after picture onset, $t(15)=-2.13, S D=0.85, p=.03$. It kept on developing and reached its maximum value around $820 \mathrm{~ms}$ after picture onset. The no-go waveform fluctuated around the baseline during the epoch, without producing a significant deviation in either a positive or negative direction. Thus, for no-go trials, no significant development of the LRP was observed,

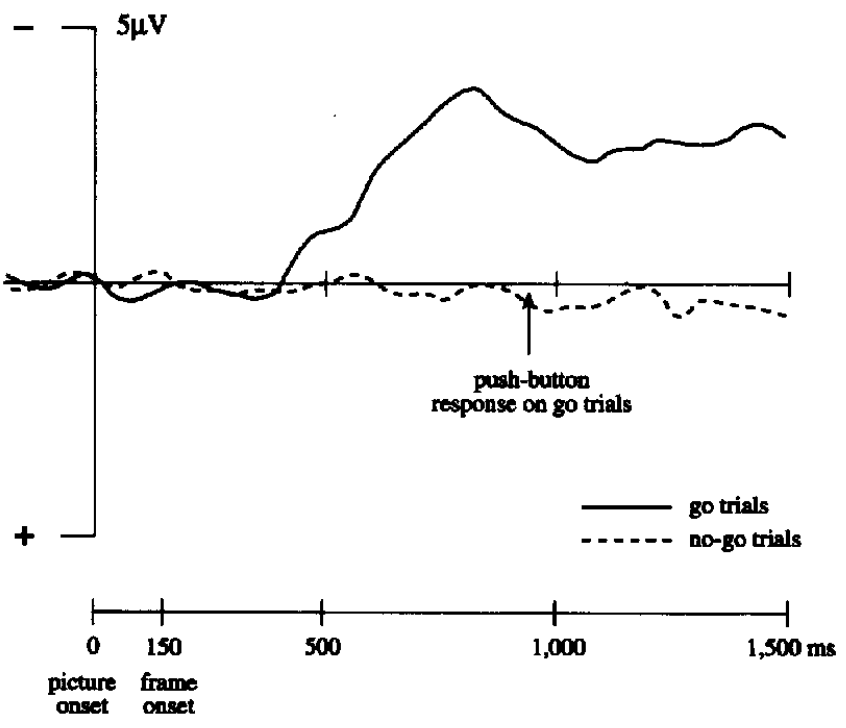

Figure 5. Grand average ( $N=16$ participants) lateralized readiness potentials on go and no-go trials of Experiment 2. The semantic decision determined whether a trial was a go or a no-go trial; the word-final phoneme decision determined the response hand. No significant lateralization of the readiness potential was obtained on no-go trials. 
indicating that no response preparation occurred on these trials.

Analyses of the go/no-go difference scores showed that the go and no-go waveforms started to diverge $410 \mathrm{~ms}$ after picture onset, $t(15)=-2.27, S D=1.05, p<.05$. This point of divergence corresponds to the onset of the LRP on go trials and confirms the absence of significant differential activity on no-go trials.

To provide information about the variation among participants, plots of individual go and no-go LRP waveforms are shown in Figure 6. The first nine plots in Figure 4 and Figure 6 show the data of participants who took part in both Experiment 1 and Experiment 2 . In these figures, it can be seen that in contrast to Experiment 1 , in Experiment 2 basically no lateralization of the readiness potential was observed on no-go trials.

To make a within-subjects comparison of the results of the two experiments, separate analyses were performed on the LRP data of the 9 participants who took part in both Experiment 1 and Experiment 2 . These analyses showed that in Experiment 1, an LRP was present on both go and no-go trials. The LRP onset latency was $370 \mathrm{~ms}$ after picture onset for the go trials, $t(8)=-1.97, S D=0.68, p<.05$, and 390 $\mathrm{ms}$ after picture onset for the no-go trials, $t(8)=-1.94$, $S D=0.84, p<.05$. In Experiment 2, a significant LRP started to develop $400 \mathrm{~ms}$ after picture onset on go trials, $t(8)=-1.91, S D=0.53, p<.05$. However, no LRP was present on no-go trials for these participants.

\section{Discussion}

The reaction time data showed that the mean response time in Experiment 2 was almost identical to the mean response latency obtained in Experiment 1. Although some care needs to be taken in comparing the mean response times of two separate participant groups, this result suggests that the specific task conditions in the two experiments did not affect the total amount of time required to give a response. The LRP data showed that whereas an LRP was present on go trials, no significant LRP was observed on no-go trials. The absence of an LRP on no-go trials in Experiment 2 indicates that on these trials, phonological information did not affect response preparation. Phonological information started to activate response hands only after the semantically based go/no-go distinction had been made. These findings support the claim that semantic information influences response preparation at an earlier moment than phonological information.

The results of Experiment 2 rule out two alternative explanations for the no-go LRP obtained in Experiment 1. The first alternative explanation is that the no-go LRP in Experiment 1 could have resulted from the automatic activation of response hands after both the semantic and the phonological analysis had been completed. If this were the case, then one could claim that the LRP observed on no-go trials did not result from the transmission of early available semantic information, but instead reflected that participants
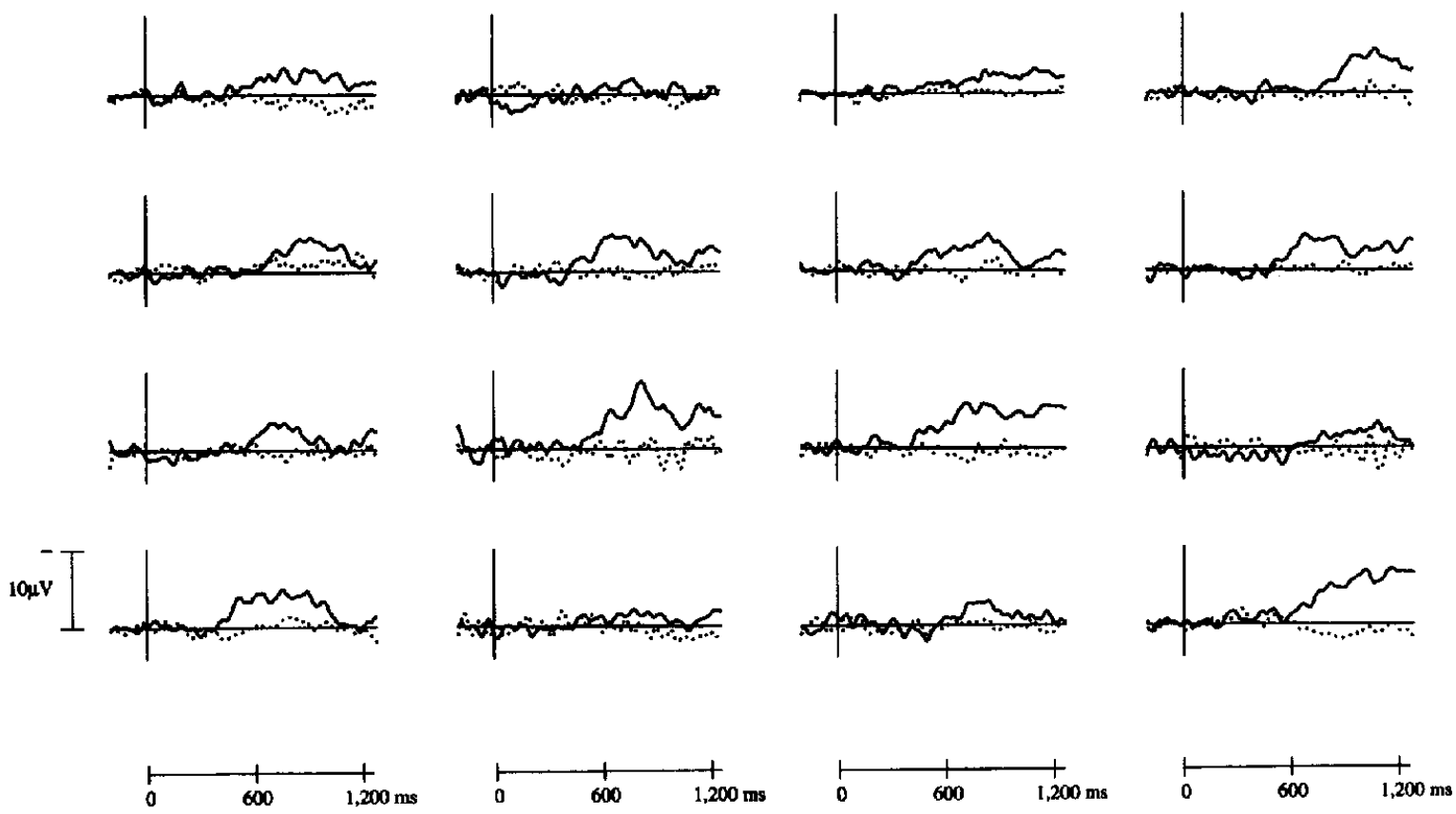

- go trials

Figure 6. Lateralized readiness potentials on go and no-go trials for each of the participants in Experiment 2 . As in Figure 4, the first nine plots, depicted from left to right, show data from the individuals who participated in both Experiments 1 and 2. 
automatically first activated the response hand, and then either withheld or executed the response. This explanation, however, is shown to be incorrect by the present data. If participants always first automatically activated the correct response hand, an LRP should have been present on no-go trials in both experiments. This is not in agreement with the results obtained in Experiment 2, and therefore this possibility can be ruled out.

A second alternative interpretation of the no-go LRP observed in Experiment 1 is that the experimental task induced participants to use a response-selection strategy. As was already mentioned in the introduction, there is some evidence indicating that participants have strategic control over the use of partial information (cf. Coles, De Jong, Gehring, \& Gratton, 1991; Smid et al., 1992). Applying a response-selection strategy means that the information discriminating between response hands is made available earlier than the go/no-go information. That is, in the special circumstances of the task in Experiment 1, participants would first complete the semantic analysis to select the response hand, and would then complete the phonological analysis to make the go/no-go decision. As a consequence, the presence of an LRP on no-go trials would not be a reflection of the early availability of semantic information during picture naming, but would just be the result of strategic use of information during the experimental task. This explanation, however, does not hold. If the effect had indeed been due to strategic control, we would have observed an LRP on no-go trials independent of whether the response hand was determined by the phonological analysis or the semantic analysis. In contrast to this prediction, our results show that the occurrence of an LRP on no-go trials was dependent on how the semantic and phonological dimensions were assigned to the response hand and go/ no-go distinctions. The results show that in Experiment 2, phonological information did not serve as partial information to selectively activate response hands before the semantically based go/no-go distinction had been made. Therefore, it seems unlikely that the no-go LRP in Experiment 1 can be explained as a strategy effect.

The only remaining option for a strategy account of our results would be one that attributes differential strategic effects to the different participant groups. Because there were different participants in the two experiments, the null effect in Experiment 2 might reflect that participants in Experiment 1 used such a strategy, whereas participants in Experiment 2 did not. However, analyses performed on the data of the 9 participants who took part in both experiments revealed that for these 9 participants a significant no-go LRP occurred in Experiment 1, whereas in Experiment 2 no LRP developed on no-go trials. This clearly shows that the possibility that the no-go LRP observed in Experiment 1 was the result of a response-selection strategy can be excluded.

Together, the results of Experiment 1 and Experiment 2 show that the LRP is differentially sensitive to the separate moments at which semantic information and word-form information become available in a semantic-phonological judgment task about pictures and their names. However, these results do not provide decisive evidence that semantic activation precedes phonological encoding in speech production. Instead of demonstrating a temporal separation between semantic activation and phonological encoding, the results might be a reflection of the temporal properties of phonological encoding itself. Although the precise nature and the timing of the subprocesses involved in phonological encoding are still a matter of investigation, current models of speech production agree that phonological word forms cannot be retrieved from the mental lexicon as entities, but rather are constructed out of segments or sequences of segments (Dell, 1988; Levelt, 1989; Meyer, 1990, 1991; Shattuck-Huffnagel, 1979). The phonological form of a word does not become available at once; time is required to make available the word's constituent phonemes and to assign them to the prosodic frame of the word. Recent reaction time studies on the time course of phonological encoding suggest that the process of constructing the phonological form of a word operates in a left-to-right manner, with the beginning of a word being encoded before its end (Meyer \& Schriefers, 1991; Wheeldon \& Levelt, 1995). These findings have the following implication for the present data. The phonological analysis we used in the experiments involved the classification of the word's final phoneme. Because there is evidence that word-form encoding proceeds from left to right, the consequence of using a word-final phoneme categorization task is that correct response selection could occur only after the main part of the phonological form of the word had already been constructed. The amount of time needed to complete this relatively extensive phonological analysis might have contributed to the temporal advantage we observed for the semantic analysis. This means that in the present data, it is unclear to what extent the no-go LRP in Experiment 1 reflected a temporal separation between semantic and phonological processing, and to what extent the no-go LRP developed as a result of the time required for constructing the word form. Therefore, we decided to run a third experiment in which we tried to minimize the time required for completing the phonological analysis.

\section{Experiment 3}

In this experiment, participants had to perform the same task as in Experiment 1, with one difference: Instead of the word-final phoneme, the word-initial phoneme determined whether a response should be executed. Thus, in Experiment 3 , the selection of a response hand was based on the animate-inanimate decision, and the go/no-go distinction was made on the basis of the word-initial phoneme.

The main purpose of this experiment was to determine whether semantic information would still be available before phonological information if the time required for phonological processing was minimized. According to the claim that semantic activation precedes phonological encoding, manipulating the duration of phonological processing should not affect the initial development of an LRP on no-go trials. Therefore, the presence of a no-go LRP would provide additional support for a temporal separation of semantic and phonological processing in speech production. If no lateral- 
ization were observed on no-go trials, then, strictly speaking, we would no longer be able to make this claim on the basis of the data from Experiments 1 and 2. The LRP obtained on no-go trials in Experiment 1 could then be explained as reflecting the additional amount of time required for the phonological encoding of the full word form relative to the phonological encoding of its onset.

Another objective of Experiment 3 was to explore the LRP's sensitivity to the temporal properties of phonological encoding itself. In Experiment 3, as in Experiment 1, the time required to complete the phonological analysis was expected to affect the time at which response preparation starts to decrease on a no-go trial. If word-form information is available later than semantic information, the offset of response preparation on no-go trials might be affected by the position of the critical phoneme in the word. If word-initial information becomes available earlier than word-final information, we expect that in Experiment 3, less time would be needed to make the go/no-go distinction. Therefore, in Experiment 3, participants might be able to decrease response preparation earlier than in Experiment 1, and as a result the interval during which the go and the no-go waveforms develop simultaneously would be reduced.

\section{Method}

\section{Participants}

Sixteen undergraduate students ( 5 male) between 20 and 27 years of age from the participant pool of the Max Planck Institute for Psycholinguistics took part in the experiment and were paid for their participation. They were all native speakers of Dutch, were all right-handed, and had normal or corrected-to-normal vision. For 5 of the participants, left-handedness occurred among direct relatives. None of the participants had any neurological impairment or had experienced any neurological trauma.

\section{Materials}

The materials consisted of 32 target pictures and 20 filler pictures. The criteria for the selection of the target pictures were identical to the criteria described for Experiment 1 and Experiment 2: The pictures had to be unambiguous, and they had to be as homogeneous as possible with respect to their recognition times.

On the basis of these criteria, we selected a set of 27 target pictures from the larger set of pictures for which naming responses and recognition times had been collected in the pretests described above. An additional 5 target pictures were selected on the basis of results of other picture-naming studies carried out at the Max Planck Institute, in which these pictures were used as targets. Although we could not directly compare the results of these experiments with the results of our pretests, the correspondence in reaction times between these 5 pictures and the set of 27 pictures was sufficiently good to include them in the experiment. The selected target pictures are listed in Appendix B.

Half of the pictures depicted animals and the other half depicted objects. The names of the target pictures had the phonemes $\mathrm{k} /, / \mathrm{s} /$, $/ \mathrm{v} /$, or $/ \mathrm{h} /$ at word-onset position. The combination of the two semantic and the four phonological categories resulted in eight sets of pictures: animal, word-initial / $/$ / (e.g., kameel [camel]); animal, word-initial /s/ (e.g., spin [spider]); animal, word-initial /v/ (e.g., vlinder [butterfly]); animal, word-initial /h/ (e.g., hond [dog]); object, word-initial /k/ (e.g., kanon [cannon]); object, word-initial /s/ (e.g., sleutel [key]); object, word-initial /v/ (e.g., vlag [flag]); object, word-initial $/ \mathrm{h}$ / (e.g., hamer [hammer]). Each of these sets consisted of 4 target pictures and 1 filler picture. The remaining 12 filler pictures had different word-initial phonemes and were presented only in the naming trials. These fillers were included to disrupt the sequence of the critical word-initial phonemes.

In addition, a set of 16 pictures was selected to serve as practice items. The set of practice pictures included 8 animals and 8 objects. There were 6 picture names starting with an $/ \mathrm{m} /$ and 6 picture names starting with a $/ \mathrm{p} /$. The other 4 picture names had different word onsets and were presented only in naming trials.

\section{Procedure}

The procedure was identical to the procedure used in Experiment 1 and Experiment 2, with the following exceptions. The actual experiment consisted of two series of four experimental blocks. One series contained all word-initial $/ \mathrm{k} /$ and $/ \mathrm{s} /$ items; the other series contained all word-initial $/ \mathrm{v} /$ and $/ \mathrm{h} /$ items. The order in which the two series were presented was counterbalanced across subjects. Each of the series was preceded by a naming block in which all pictures of that series were presented once. This block served as a practice block to familiarize participants with the pictures. In each of the series, target pictures were presented six times in critical judgment trials and four times in naming trials. The eight filler pictures that had critical phonemes at the word-onset position were presented four times in filler judgment trials and six times in naming trials. The other filler pictures were presented four times in naming trials. As a result, as in the previous experiments, half of the trials were naming-only trials, and the other half had the judgment task in addition.

An experimental block included 24 critical judgment trials, 4 filler judgment trials, and 28 naming trials. Each block lasted 6 min.

Apparatus, electrophysiological recordings, and data analysis were the same as those described for Experiment 1.

\section{Results}

\section{Overt Responses}

The mean push-button latency for the correct go trials was $669 \mathrm{~ms}(S D=213)$, measured from frame onset; the mean response latencies for animals and objects were $640 \mathrm{~ms}$ $(S D=199)$ and $697 \mathrm{~ms}(S D=221)$, respectively. The error rate was $7.2 \%$ for the go trials and $2.2 \%$ for the no-go trials. These error trials included all trials in which EMG errors occurred. As in Experiment 1 and Experiment 2, the errors were not further analyzed.

The mean naming latency for the experimental pictures in the naming-only trials was $720 \mathrm{~ms}$, measured from picture onset.

\section{Lateralized Readiness Potentials}

In total, $19 \%$ of the trials were excluded from the data set because of naming errors, EMG errors, and EEG artifacts. The rejected trials were equally distributed across conditions and participants. Per participant, the minimum number of trials left for averaging was 35 per condition.

Figure 7 shows the averaged LRP waveforms for the go and the no-go trials. In this figure, it can be seen that a negative LRP developed on both go and no-go trials. This 


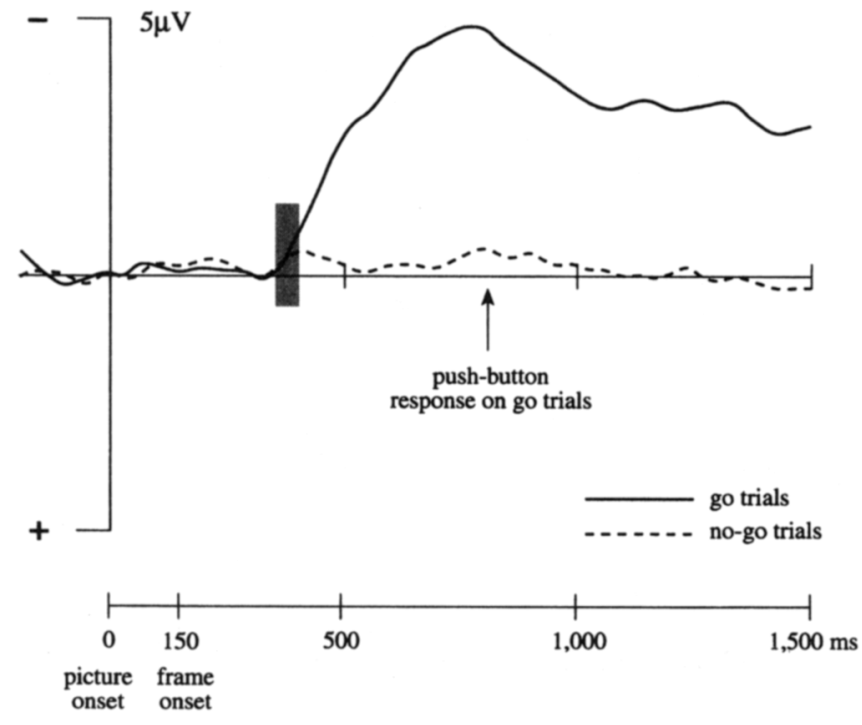

Figure 7. Grand average ( $N=16$ participants) lateralized readiness potentials (LRPs) on go and no-go trials of Experiment 3. The semantic decision determined the response hand; the word-initial phoneme decision determined whether a trial was a go or a no-go trial. As in Experiment 1, a significant lateralization of the readiness potential was obtained on no-go trials. The shaded area shows the time interval in which the go and the no-go LRPs were significantly different from the baseline but not from each other.

indicates that response preparation for the cued response hand occurred on both go and no-go trials. On go trials the LRP started to deviate significantly from zero at $360 \mathrm{~ms}$ after picture onset, $t(15)=-1.89, S D=1.09, p=.05$. The LRP kept on developing and reached its maximum around 780 ms. On no-go trials, the LRP became significant $350 \mathrm{~ms}$ after picture onset, $t(15)=-1.88, S D=0.62, p=.05$. For a short period of time, the no-go LRP developed at the same rate as the LRP for go triais.

To provide information about the variation among participants, plots of individual go and no-go LRP waveforms are shown in Figure 8. In this figure, it can be seen that for most of the participants a lateralization of the readiness potential was observed on both go and no-go trials.

At $400 \mathrm{~ms}$ after picture onset, the no-go waveform started to diverge significantly from the go waveform, $t(15)=$ $-2.24, S D=1.41, p=.03$. Whereas the LRP kept on developing for go trials, the no-go waveform returned to the baseline. $^{4}$

\section{Discussion}

Experiment 3 yielded two important results. First, we replicated the finding of an LRP on no-go trials. We found that for a short period of time, an LRP developed at the same rate on both go and no-go trials. This means that as in Experiment 1, initial response preparation occurred independently of the outcome of the go/no-go distinction. These findings show that semantic information was used for response preparation earlier than phonological information, independent of whether the phonological analysis involved the word-initial or word-final phoneme. Therefore, they support the claim that semantic information about a picture is available earlier than word-form information.

The other important finding concerns the point of divergence between the go and the no-go waveforms. The results showed that the LRP developed at the same rate on go and no-go trials from $360 \mathrm{~ms}$ to $400 \mathrm{~ms}$ after picture onset. At $400 \mathrm{~ms}$ after picture onset, the no-go waveform started to return to the baseline while the LRP kept on developing on go trials. This indicates that already at $40 \mathrm{~ms}$ after LRP onset, sufficient phonological information was available to make the go/no-go distinction. When we compare this period with the 120 -ms period in which the go and no-go LRP developed simultaneously in Experiment 1, it is evident that word-onset information was available for response preparation at an earlier moment than word-final information was. In addition to providing a new source of evidence for the idea that the word form is constructed in a left-toright manner, these results show that the LRP is sensitive to the time course of processes involved in phonological encoding. We further elaborate on these results in the General Discussion.

In addition to the LRP measurements, for each of the go and no-go conditions, average waveforms were computed for the electrode sites $\mathrm{Fz}, \mathrm{Cz}$, and $\mathrm{Pz}$. In Figure 9, the averaged waveforms for the electrode site $\mathrm{Pz}$ in Experiments 1,2 , and 3 are shown. We expected no differences to occur in the waveforms for the separate conditions, except for a difference in the amplitude of the P300 in the go and the no-go conditions. The P300 is a component of the ERP signal that is characterized by a positive going deflection that peaks around $300 \mathrm{~ms}$ after the onset of the stimulus that elicited it. The amplitude of the P300 is known to be influenced by the extent to which information about a stimulus is extracted by the participant (cf. Fabiani, Gratton, Karis, \& Donchin, 1987; Johnson, 1988). Therefore, if we observed a difference in P300 amplitude between go and no-go trials, this would indicate that more extensive stimulus processing was going on when an actual two-choice response was required than when no choice response was required. The $\mathrm{P} 300$ component varies not only in amplitude but can also vary in its latency. The latency of the P300 is assumed to depend on the time required for stimulus evaluation (cf. Donchin \& Coles, 1988; Fabiani et al., 1987). For our study, we did not expect P300 latencies to differ across the separate conditions because the stimuli we used were matched in complexity, and the experiment was

\footnotetext{
${ }^{4}$ As can be seen in Figure 7, after returning to the baseline, the no-go LRP started to develop again around $720 \mathrm{~ms}$ after picture onset. In some of the LRP studies reported in the literature, a similar reappearance of an LRP on no-go trials can be observed (cf. Osman et al., 1992; Smid et al., 1992), although it is unclear whether these LRPs are significantly different from the baseline. We do not have an explanation for this effect. However, because the no-go LRP returned to the baseline after its initial development and appeared again at the latency that a response was actually given on go trials, it is reasonable to assume that this effect has no implications for the early processes we are interested in.
} 

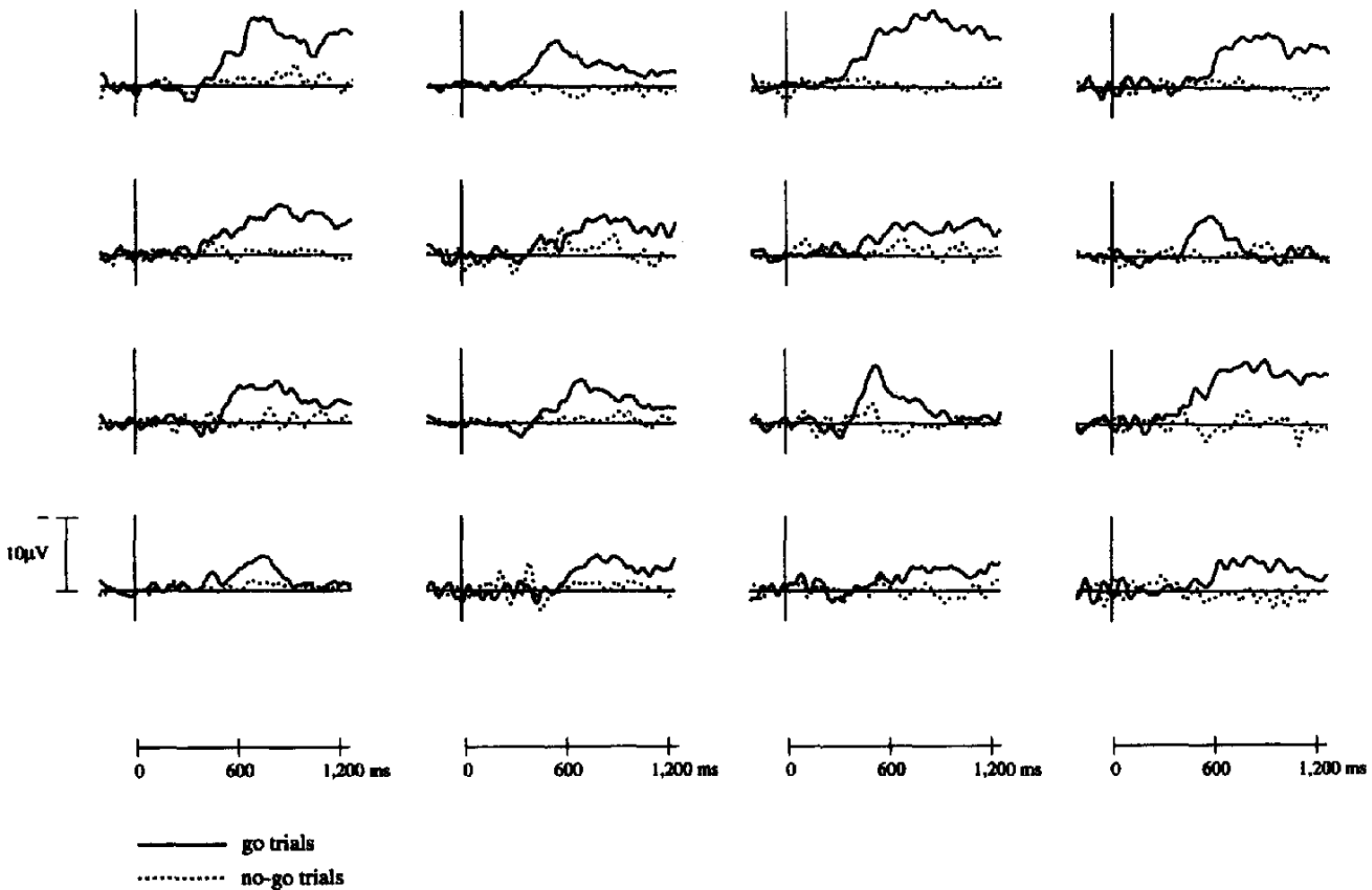

Figure 8. Lateralized readiness potentials on go and no-go trials for each of the participants in Experiment 3.

designed in such a way that each stimulus contributed equally to each of the conditions.

As can been seen in Figure 9, in all three experiments the P300 amplitude was larger in the go conditions than in the no-go conditions. To further analyze this difference, for each of the conditions, mean amplitudes were computed in the latency range of $250-450 \mathrm{~ms}$ after frame onset. In addition, mean positive peak latencies were determined for each of the conditions. On both the mean amplitudes and the mean peak latencies, a repeated measures analysis of variance (ANOVA) was performed with participants, electrode site
$(\mathrm{Fz}, \mathrm{Cz}$, and $\mathrm{Pz}$ ), response side (left or right), and response (go or no-go) as completely crossed variables. In addition to these overall analyses, similar analyses were performed for each electrode site separately. The mean amplitude differences (averaged over the electrode sites $\mathrm{Fz}, \mathrm{Cz}$, and $\mathrm{Pz}$ ) between the go and the no-go trials that were in the $250-450$-ms range after frame-onset latency were $3.7 \mu \mathrm{V}$, $3.1 \mu \mathrm{V}$, and $2.9 \mu \mathrm{V}$ in Experiments 1, 2, and 3, respectively. In an ANOVA, this difference was statistically significant for each of the experiments: Experiment $1, F(1,15)=65.37$, $M S E=144.52, p<.01 ;$ Experiment $2, F(1,15)=21.50$,
Experiment 1

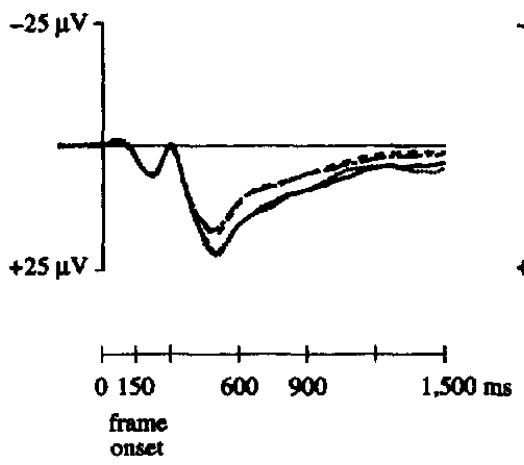

Experiment 2

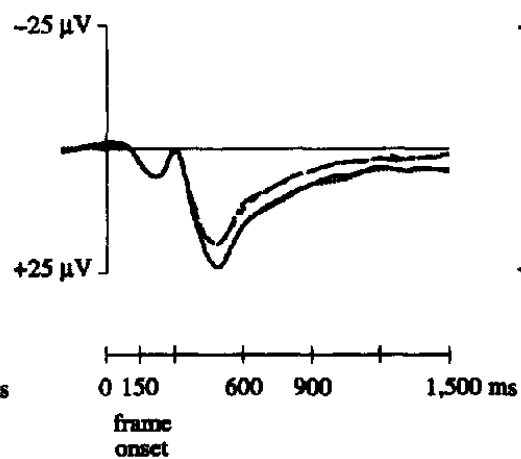

Experiment 3

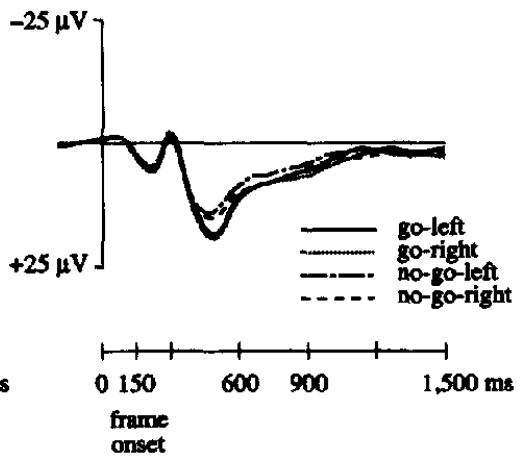

Figure 9. Grand average ( $N=16$ participants) event-related potentials from the electrode site $\mathrm{Pz}$ for go and no-go trials of Experiments 1,2, and 3 in which either the left or the right hand was cued. 
$M S E=327.19, p<.01$; Experiment $3, F(1,15)=32.42$, $M S E=188.34, p<.001$. There was no effect of response side $(F<1)$ in any of the experiments, and there were no significant interactions. For all three experiments, the mean peak latencies of the P300 did not significantly differ for go and no-go trials $(F<1)$.

Thus, as predicted, we found that a larger P300 was elicited in go trials than in no-go trials, but that no P300 latency differences emerged across the conditions. This indicates that although more processing was required on trials in which a push-button response had to be executed, the time needed to evaluate the target pictures was equal across conditions. In summary, the results of these midline recordings do not bear directly on the experimental questions, but serve as an indirect validation of the materials used in the experiments and as an indication of the reliability of the LRP recordings.

\section{General Discussion}

In the present study, we have developed a new experimental paradigm in which we used the LRP to investigate the time course of semantic activation and phonological encoding in speech production.

In Experiment 1, an LRP was observed on no-go trials, indicating that semantic information was used to activate the response hand, independent of whether the word-final phoneme decision cued a response. In Experiment 2, we found that a word-final phoneme decision resulted in an LRP only on trials in which the semantic decision cued a response. In Experiment 3, we demonstrated that when the phonological decision involved the word-initial phoneme instead of the word-final phoneme, again a no-go LRP developed on the basis of semantic information.

The presence of an LRP on no-go trials in both Experiment 1 and Experiment 3 indicates that semantic information about a picture affects response preparation before sufficient phonological information about the picture name is available. The absence of a no-go LRP in Experiment 2 substantiates this claim of temporal priority for semantic information over phonological information. Also, it rules out the possibilities that the early response preparation observed on no-go trials in Experiment 1 and Experiment 3 was either generated automatically following the simultaneous availability of both types of information or was due to strategic control over the use of partial information.

Before turning to the implications of the present results, two issues related to the experimental procedure need to be discussed. The first concerns the possible effects of picture repetition. Could the multiple presentation of each picture have affected the nature of the naming process? In unpublished picture-word interference experiments carried out at our institute, it has been shown that repeating pictures speeds up naming latencies but does not interact with semantic or phonological relatedness effects. This indicates that each time a picture is named, the same production processes are involved, independent of the number of repetitions. Another effect of repeating pictures could be that after having given the same response to a picture a couple of times, a response might be given on the basis of the visual recognition of the picture alone. However, such an effect could not have contributed to the development of a no-go LRP. On the contrary, one would expect a no-go LRP to disappear if such a stimulus--response coupling had been made.

The second issue related to the experimental procedure concerns the possibility of strategic effects due to (putative) differences in difficulty of the phonological decision task compared with the animacy decision task. It could be claimed that the animacy decision task is somehow intrinsically simpler than the phonological decision task, and that individuals use the strategy of always performing the easier task first. This strategy could lead to the pattern of effects we obtained. According to this account, the observed initial development of the LRP on no-go trials would have resulted from a strategic choice to perform the animacy decision first and then the phonological task, because the phonological task was more difficult. However, recent evidence from our laboratory indicates that the intuitively supposed differences in the complexity of the decision tasks do not determine the order in which different kinds of information are used for response selection. In an experimental paradigm similar to the one reported here, the word-initial phoneme decision task was combined with a grammatical gender decision task. Although the conscious retrieval of the grammatical gender of a picture name is intuitively more complex than the retrieval of a word's initial phoneme, the data show that gender information affected response preparation earlier than word-onset information. This finding allows us to argue against the position that the present LRP data were mainly caused by strategy effects induced by differences in task difficulty.

In summary, the present results demonstrate that the LRP is differentially sensitive to the moments at which semantic and phonological properties of pictures and their names become available for response preparation. Under the plausible assumption that the availability of semantic and phonological properties of a picture name are a reflection of the time course of speech production, we can conclude that the LRP paradigm provides insight into the relative timing of semantic activation and phonological encoding in speech production. What, then, do the present results reveal about speech production?

One of the aims of this study was to show that during speech production, semantic activation precedes phonological encoding. The following findings provide evidence for early semantic activation in speech production.

In Experiment 1 and Experiment 3, we found that for a short period of time an LRP developed not only on go but also on no-go trials. The go and no-go LRPs had approximately the same onset latencies, and they developed at the same rate. From these results, we can conclude that semantic properties of a picture are used to selectively activate response hands before either the word-final phoneme (Experiment 1) or the word-initial phoneme (Experiment 3) of the picture name is available to suppress the response preparation. The absence of a no-go LRP in Experiment 2 shows that the semantic properties of the picture were available to 
make the go/no-go distinction before word-final phoneme information was used to prepare response hands.

Other evidence for the early availability of semantic information comes from a comparison of the results obtained for go trials in the three experiments. As mentioned earlier, we have to be careful in interpreting the outcomes of direct comparisons of response or LRP onset latencies obtained in the separate experiments. Because different participant groups contributed to the experiments, these comparisons do not provide exact quantitative estimations of the semantic and phonological processing times. Rather, these comparisons can provide more insight into whether differences in the time course of semantic and phonological processing were at all present.

First, when comparing the results obtained for go trials in Experiment 1 and Experiment 2, we see that whereas the mean response latencies were almost identical in both experiments, the go LRPs tended to start at an earlier moment in Experiment 1 than in Experiment 2. In both experiments, a correct go response could be given only when both the semantic and the word-final phoneme analyses had been completed. The difference, however, was that in Experiment 1 the selection of the response hand could be made during the stage of semantic activation, whereas in Experiment 2 this selection could be made only after the word form had been constructed. The reaction time data suggest that this manipulation did not affect the moment at which the response was carried out. However, the observed difference in LRP onset latencies suggests that response preparation started earlier in Experiment 1 than in Experiment 2.

Second, the go trials in Experiment 1 resulted in substantially longer reaction times than the go trials in Experiment 3 , in the absence of such a difference for the LRP onset latencies. This finding suggests that in both experiments, semantic information was used to selectively prepare response hands at about the same moment. Manipulating the position of the critical phoneme in the word thus did not influence the onset of response preparation but did affect the time required to complete the go/no-go decision.

Taken together, these findings are consistent with the claim that in the initial phase of speech production, the semantic properties of the to-be-pronounced word are activated, whereas the phonological form of the word has not yet been encoded. We cannot conclude from these data whether the stages of semantic activation and phonological encoding are discrete. Although we have demonstrated that semantic activation precedes phonological encoding, there might still be some overlap between the final part of the semantic stage and the start of phonological encoding. Now that the LRP paradigm has been shown to be sensitive to the time course of lexical access in speech production, this issue of the exact temporal profile can be addressed in future research.

In addition to the relative timing of semantic and phonological processing, the LRP results also provide more insight into the time course of phonological encoding itself. As we have argued, in Experiments 1 and 3 the point of divergence between the go and the no-go waveforms was determined by the moment at which the word's critical phoneme was available. The idea that the point of divergence between the go and the no-go waveforms can be used as an estimate of the time course of phonological encoding is validated by the following. For Experiment 1, we subtracted the no-go waveform from the go waveform. The resulting go/no-go difference waveform is shown in Figure 10. This difference waveform reflects the impact of the go/no-go decision on response preparation. Its onset provides an estimate of when word-final phoneme information decreased response preparation on no-go trials in Experiment 1. Also shown in this figure is the LRP for go trials, obtained in Experiment 2, where the word-final phoneme decision determined the response hand. The onset of this go waveform reveals when word-final phoneme information affected the LRP. The observed correspondence between the difference waveform in Experiment 1 and the go LRP in Experiment 2 suggests that the phonological information affected the development of the LRP at roughly the same moment, independent of whether the phonological decision was assigned to the response hand or to the go/no-go dimension. From this we infer that the period during which the go and the no-go LRPs developed simultaneously provides an estimate of the additional time needed for phonological encoding, after the picture's semantic properties have been retrieved. Thus, the duration of the no-go LRP can be used as an estimate for the extra time needed to retrieve the critical phoneme of the picture name. Because this period is measured within subjects, a straightforward comparison is possible.

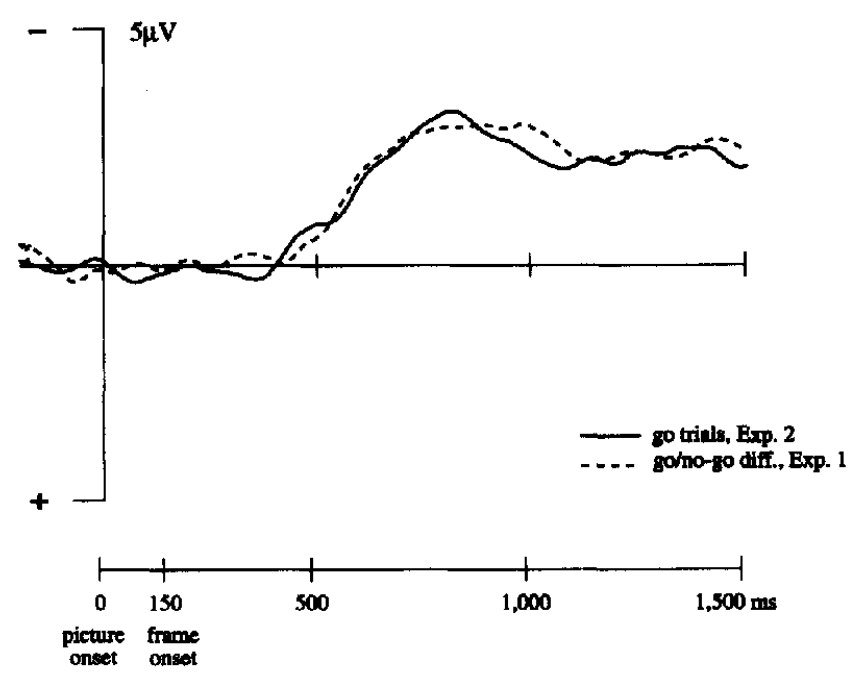

Figure 10. Grand average ( $N=16$ participants) waveforms from Experiment 1 and Experiment 2. The solid waveform shows the lateralized readiness potential on go trials in Experiment 2, where the go/no-go decision was based on the meaning of the words and the word-final phoneme decision determined which hand to use. The dashed waveform represents the go/no-go difference waveform obtained in Experiment 1, where the go/no-go decision was based on the word-final phoneme and the meaning of the word determined which response hand to use. The moment at which the go/no-go difference waveform diverges from the baseline provides an estimate of when the phonological information decreased response preparation on no-go trials. Exp. = experiment; diff. = difference. 
With these findings in hand, we return to the difference we observed between the duration of the no-go LRPs in Experiment 1 and Experiment 3. In Experiment 1, the word-final phoneme was critical for making the go/no-go distinction, and here we found that $120 \mathrm{~ms}$ after LRP onset, response preparation was decreased on no-go trials. In Experiment 3, where the word-initial phoneme was critical for making this distinction, only $40 \mathrm{~ms}$ were required to decrease the response. This $80-\mathrm{ms}$ difference in the duration of response preparation on no-go trials is most likely related to the time course of the phonological encoding from the beginning of the target word to its end. It supports the idea that phonological encoding proceeds in a left-to-right manner, with the onset of a word being encoded before its end. ${ }^{5}$ On the basis of this finding, we estimate that for words consisting of an average of 1.5 syllables and 4.5 phonemes, it takes about $80 \mathrm{~ms}$ longer to encode the end of a word than to encode its beginning.

This estimation is consistent with the data from phonememonitoring experiments reported by Wheeldon and Levelt (1995). In their study, Wheeldon and Levelt asked Dutch participants to detect a given phoneme in an internally produced Dutch word translated from an English target word. They found that for disyllabic words, the difference between monitoring latencies for phonemes at the first and the last position of a syllable was on average $55 \mathrm{~ms}$, and the difference between monitoring the first and the last phoneme of a word was approximately $124 \mathrm{~ms}$. Taking into account that the words in our study were shorter than the words used by Wheeldon and Levelt (our words had an average length of 1.5 syllables, and Wheeldon \& Levelt's, 1995, words were all disyllabic), these findings correspond nicely to the 80-ms estimate we made for the duration of phonological encoding from word onset to word offset.

Now we go back to the overall results in Experiment 1. As already mentioned above, the time between the onset of the LRPs and the onset of the go/no-go difference waveform was $120 \mathrm{~ms}$. What does this tell us about the length of phonological encoding? According to a strict two-stage model of speech production, phonological encoding can start only after a lemma has been selected. If we assume that at LRP onset the lemma has been selected, we can interpret the period in between the onset of the LRPs and the onset of the go/no-go difference waveform as an estimation of the time required to make available the critical phoneme. According to this view, the period of $120 \mathrm{~ms}$ found in Experiment 1 can be taken as an estimation of the time required to construct a word form from its beginning to its end, for words that on average consist of 1.5 syllables and 4.5 phonemes. Following the same line of reasoning, the period of $40 \mathrm{~ms}$ observed in Experiment 3 can be interpreted as an estimation of the time required to encode the onset of a word.

However, perhaps the assumptions we are making are too strong. On the basis of our data, we cannot claim that phonological encoding started after lemma selection. Moreover, given the nature of our semantic task, it is not clear whether the semantic decision involved lemma selection. It could be that the semantic property animacy became avail- able during an earlier phase of conceptual identification. Irrespective of which assumptions apply, what we can infer from the data is that once a semantic candidate has been retrieved, it takes an additional $120 \mathrm{~ms}$ to encode its word form.

In conclusion, we have demonstrated that the LRP can be used to track the time course of processes involved in speech production, and we have provided evidence for the claim that in speech production there is an initial phase of semantic activation, followed by a stage of phonological encoding. Furthermore, on the basis of the LRP data, we estimate that for words consisting of an average of 1.5 syllables and 4.5 phonemes, it takes $80 \mathrm{~ms}$ longer to retrieve a word's final phoneme than to retrieve its beginning. Finally, we observed that it takes $120 \mathrm{~ms}$ longer to retrieve the final phoneme of a word than to retrieve its semantic category. This $120-\mathrm{ms}$ interval can be interpreted as the additional amount of time needed to phonologically encode a word once the semantic candidate has been retrieved.

By introducing the LRP go/no-go paradigm into the field of speech-production research, we have been able to show that ERPs can be used to observe the rapid mental processes that underlie speaking. This novel finding opens the way for a more fine-grained real-time analysis of speech production than has hitherto been possible.

\footnotetext{
${ }^{5}$ However, one problem that arises when drawing inferences from the LRP data about the temporal properties of phonological encoding concerns the nature of the phoneme decision task. Are the word's constituent phonemes transmitted to the response processes as soon as they are spelled out, or do they become available in a later phase of phonological processing? The present experiments were not designed to distinguish between separate levels of phonological encoding, and therefore further research is required to examine the precise locus of the phonological effects obtained in this study.
}

\section{References}

Baars, B. J., Motley, M. T., \& MacKay, D. G. (1975). Output editing for lexical status in artificially elicited slips of the tongue. Journal of Verbal Learning and Verbal Behavior, 14, 382-391.

Bock, J. K. (1982). Toward a cognitive psychology of syntax: Information processing contributions to sentence formulation. Psychological Review, 89, 1-47.

Bock, J. K. (1986). Meaning, sound, and syntax: Lexical priming in sentence production. Journal of Experimental Psychology: Learning, Memory, and Cognition, 12, 575-586.

Brown, A. S. (1991). A review of the tip-of-the-tongue experience. Psychological Bulletin, 109, 204-223.

Butterworth, B. (1980). Some constraints on models of language production. In B. Butterworth (Ed.), Language production: Vol 1. Speech and talk (pp. 423-459). London: Academic Press.

Butterworth, B. (1989). Lexical access in speech production. In W. Marslen-Wilson (Ed.), Lexical representation and process (pp. 108-135). Cambridge, MA: MIT Press.

Coles, M. G. H. (1989). Modern mind-brain reading: Psychophysiology, physiology, and cognition. Psychophysiology, 26, 251269.

Coles, M. G. H., De Jong, R., Gehring, W. J., \& Gratton, G. (1991). Continuous versus discrete information processing: Evidence 
from movement-related potentials. In C. H. M. Brunia, G. Mulder, \& M. N. Verbaten (Eds.), Event-related brain research: Electroencephalography and clinical neurophysiology (Suppl. 42, pp. 260-269). Amsterdam: Elsevier.

Coles, M. G. H., Gratton, G., Bashore, T. R., Eriksen, C. W., \& Donchin, E. (1985). A psychophysiological investigation of the continuous flow model of human information processing. Journal of Experimental Psychology: Human Perception and Performance, $11,529-553$.

Coles, M. G. H., Gratton, G., \& Donchin, E. (1988). Detecting early communication: Using measures of movement-related potentials to illuminate human information processing. Biological Psychology, 26, 69-89.

Coles, M. G. H., Smid, H. G. O. M., Scheffers, M. K., \& Otten, L. J. (1995). Mental chronometry and the study of human information processing. In M. D. Rugg \& M. G. H. Coles (Eds.), Electrophysiology of mind: Event-related brain potentials and cognition (pp. 86-113). New York: Oxford University Press.

Deecke, L., Engel, M., Lang, W., \& Kornhuber, H. H. (1986). Bereitschaftspotential preceding speech after holding breath. Experimental Brain Research, 65, 219-223.

De Jong, R., Wierda, M., Mulder, G., \& Mulder, L. J. M. (1988). Use of partial information in responding. Joumal of Experimental Psychology: Human Perception and Performance, 14, 682692.

Dell, G. S. (1986). A spreading activation theory of retrieval in sentence production. Psychological Review, 93, 283-321.

Dell, G. S. (1988). The retrieval of phonological forms in production: Tests of predictions from a connectionist model. Journal of Memory and Language, 27, 124-142.

Dell, G. S., \& O'Seaghdha, P. G. (1991). Mediated and convergent lexical priming in language production: A comment on Levelt et al. (1991). Psychological Review, 98, 604-614.

Dell, G. S., \& O'Seaghdha, P. G. (1992). Stages of lexical access in language production. Cognition, 42, 287-314.

Dell, G. S., \& Reich, P. A. (1981). Stages in sentence production: An analysis of speech error data. Journal of Verbal Learning and Verbal Behavior, 20, 611-629.

Donchin, E., \& Coles, M. G. H. (1988). Is the P300 component a manifestation of context updating? Behavioral and Brain Sciences, 11, 355-372.

Eriksen, C. W., Coles, M. G. H., Morris, L. R., \& O'Hara, W. P. (1985). An electromyographic examination of response competition. Bulletin of the Psychonomic Society, 23, 165-168.

Fabiani, M., Gratton, G., Karis, D., \& Donchin, E. (1987). Definition, identification, and reliability of measurements of the P300 component of the event-related brain potential. In P. K. Ackles, J. R. Jennings, \& M. G. H. Coles (Eds.), Advances in psychophysiology (Vol. 2, pp. 1-78). Greenwich, CT: JAI Press.

Fromkin, V. A. (1971). The nonanomalous nature of anomalous utterances. Language, 47, 27-52.

Garrett, M. F. (1975). The analysis of sentence production. In G. Bower (Ed.), The psychology of learning and motivation: Advances in research and theory (Vol. 9, pp. 133-175). New York: Academic Press.

Garrett, M. F. (1976). Syntactic processes in sentence production. In R. J. Wales \& E. C. T. Walker (Eds.), New approaches to language mechanisms (pp. 231-256). Amsterdam: NorthHolland.

Garrett, M. F. (1988). Processes in language production. In F. J. Newmeyer (Ed.), The Cambridge survey of linguistics: Vol. III. Biological and psychological aspects of language (pp. 69-96). Cambridge, MA: Harvard University Press.

Glaser, W. R. (1992). Picture naming. Cognition, 42, 61-105.

Gratton, G., Coles, M. G. H., \& Donchin, E. (1992). Optimizing the use of information: Strategic control of activation of responses. Journal of Experimental Psychology: General, 121, 480-506.

Gratton, G., Coles, M. G. H., Sirevaag, E., Eriksen, C. W., \& Donchin, E. (1988). Pre- and poststimulus activation of response channels: A psychophysiological analysis. Journal of Experimental Psychology: Human Perception and Performance, 14, 331344.

Grözinger, B., Kornhuber, H. H., \& Kriebel, J. (1977). Human cerebral potentials preceding speech production, phonation, and movements of the mouth and tongue, with reference to respiratory and extracerebral potentials. In J. E. Desmedt (Ed.), Language and hemispheric specialization in man: Cerebral ERPs (pp. 87-103). Basel, Switzerland: Karger.

Hagoort, P., Brown, C. M., \& Groothusen, J. (1993). The syntactic positive shift (SPS) as an ERP measure of syntactic processing Language and Cognitive Processes, 8, 439-483.

Harley, T. A. (1984). A critique of top-down independent level models of speech production: Evidence from non-plan-internal speech errors. Cognitive Science, 8, 191-219.

Harley, T. A. (1993). Phonological activation of semantic competitors during lexical access in speech production. Language and Cognitive Processes, 8, 291-310.

Hillyard, S. A., Mangun, G. R., Woldorff, M. G., \& Luck, S. J. (1995). Neural systems mediating selective attention. In M. S. Gazzaniga (Ed.), The cognitive neurosciences (pp. 665-681). Cambridge MA: MIT Press.

Hillyard, S. A., \& Münte, T. F. (1984). Selective attention to colour and locational cues: An analysis with event-related brain potentials. Penception and Psychophysics, 36, 185-198.

Howard, D., \& Franklin, S. (1989). Missing the meaning? Cambridge, MA: MIT Press.

International Phonetic Association. (1967). The principles of the International Phonetic Association. London: University College.

Jasper, H. H. (1958). Report to the committee on methods and clinical examination in electroencephalography. Appendix: The ten-twenty system of the International Federation. Electroencephalography and Clinical Neurophysiology, 10, 371-375.

Johnson, R., Jr. (1988). The amplitude of the P300 component of the event-related potential: Review and synthesis. In P. K. Ackles, J. R. Jennings, \& M. G. H. Coles (Eds.), Advances in psychophysiology (Vol. 3, pp. 69-137). Greenwich, CT: JAI Press.

Kay, J., \& Ellis, A. (1987). A cognitive neuropsychological case study of anomia: Implications for psychological models of word retrieval. Brain, 110, 610-629.

Kempen, G. (1977). Conceptualizing and formulating in sentence production. In S. Rosenberg (Ed.), Sentence production: Developments in research and theories. Hillsdale, NJ: Erlbaum.

Kempen, G., \& Hoenkamp, E. (1987). An incremental procedural grammar for sentence formulation. Cognitive Science, 11, 201258 .

Kempen, G., \& Huijbers, P. (1983). The lexicalization process in sentence production and naming: Indirect election of words. Cognition, 14, 185-209.

Kornhuber, H. H., \& Deecke, L. (1965). Hirnpotentialanderungen bei Willkurbewegungen und passiven Bewegungen des Menschen: Bereitschaftspotential und reafferente Potentiale [Brain potential changes associated with voluntary and passive movements in humans: Readiness potential and reafferent potentials]. Pfluger's Archive, 284, 1-17.

Kutas, M., \& Donchin, E. (1974, November 8). Studies of squeezing: Handedness, responding hand, response force, and asymmetry of readiness potential. Science, 186, 545-548.

Kutas, M., \& Donchin, E. (1977). The effects of handedness, of responding hand, and of response force on the contralateral dominance of the readiness potential. In J. Desmedt (Ed.), 
Attention, voluntary contraction, and event-related potentials (pp. 189-210). Basel, Switzerland: Karger.

Kutas, M., \& Donchin, E. (1980). Preparation to respond as manifested by movement-related brain potentials. Brain $R e$ search, 202, 95-115.

Kutas, M., \& Hillyard, S. A. (1980, January 11). Reading senseless sentences: Brain potentials reflect semantic incongruity. Science, 207, 203-205.

Kutas, M., \& Van Petten, C. (1988). Event-related brain potential studies of language. In P. K. Ackles, J. R. Jennings, \& M. G. H. Coles (Eds.), Advances in psychophysiology (Vol. 3, pp. 139187). Greenwich, CT: JAI Press.

Levelt, W. J. M. (1983). Monitoring and self-repair in speech. Cognition, 14, 41-104.

Levelt, W. J. M. (1989). Speaking: From intention to articulation. Cambridge, MA: MIT Press.

Levelt, W. J. M., Schriefers, H., Vorberg, D., Meyer, A. S., Pechmann, T., \& Havinga, J. (1991). The time course of lexical access in speech production: A study of picture naming. Psychological Review, 98, 122-142.

Martin, N., Gagnon, D. A., Schwartz, M. F., Dell, G. S., \& Saffran, E. M. (1996). Phonological facilitation of semantic errors in normal and aphasic speakers. Language and Cognitive Processes, 11, 257-282.

Martin, N., Weisberg, R. W., \& Saffran, E. M. (1989). Variables influencing the occurrence of naming errors: Implications for models of lexical retrieval. Joumal of Memory and Language, $28,462-485$.

McAdam, D. W., \& Whitaker, H. A. (1971, April 30). Electroencephalographic localization in the normal human brain. Science, $172,499-502$.

Meyer, A. S. (1990). The time course of phonological encoding in language production: The encoding of successive syllables of a word. Joumal of Memory and Language, 29, 524-545.

Meyer, A. S. (1991). The time course of phonological encoding in language production: Phonological encoding inside a syllable. Journal of Memory and Language, 30, 69-89.

Meyer, A. S. (1992). Investigation of phonological encoding through speech error analyses: Achievements, limitations, and alternatives. Cognition, 42, 181-211.

Meyer, A. S., \& Schriefers, H. (1991). Phonological facilitation in picture-word interference experiments: Effects of stimulus onset asynchrony and types of interfering stimuli. Journal of Experimental Psychology: Learning, Memory, and Cognition, 17, 1146-1160.

Miller, J., \& Hackley, S. A. (1992). Electrophysiological evidence for temporal overlap among contingent mental processes. Journal of Experimental Psychology: General, 121, 195-209.

Miller, J. O. (1991). Discrete versus continuous information processing: Introduction and psychophysiology. In C. H. M. Brunia, G. Mulder, \& M. N. Verbaten (Eds.), Event-related brain research: Electroencephalography and clinical neurophysiology (Suppl. 42, pp. 244-259). Amsterdam: Elsevier.

Näätänen, R. (1990). The role of attention in auditory information processing as revealed by event-related potentials and other brain measures of cognitive function. Behavioral and Brain Sciences, 13, 201-288.

Oldfield, R. C. (1971). The assessment of the analysis of handedness: The Edinburgh inventory. Neuropsychologica, 9, 97-113.

Osman, A., Bashore, T. R., Coles, M. G. H., Donchin, E., \& Meyer, D. E. (1992). On the transmission of partial information: Inferences from movement-related brain potentials. Journal of
Experimental Psychology: Human Perception and Performance, $18,217-232$.

Osterhout, L., \& Holcomb, P. (1992). Event-related brain potentials elicited by syntactic anomaly. Journal of Memory and Language, 31, 785-806.

Petersen, S. E., \& Fiez, J. A. (1993). The processing of single words studied with positron emission tomography. Annual Review of Neuroscience, 16, 509-530.

Roelofs, A. (1992). A spreading-activation theory of lemma retrieval in speaking. Cognition, 42, 107-142.

Rohrbaugh, J. W., Syndulko, K., \& Lindsley, D. B. (1976, March 12). Brain components of the contingent negative variation in humans. Science, 191, 1055-1057.

Ruchkin, D. S., \& Glaser, E. M. (1978). Simple digital filters for examining $\mathrm{CNV}$ and $\mathrm{P} 300$ on a single-trial basis. In D. A. Otto (Ed.), Multidisciplinary perspectives in event-related brain potential research (pp. 579-581). Washington, DC: U.S. Government Printing Office.

Rugg, M. D. (1995). Event-related potential studies of human memory. In M. S. Gazzaniga (Ed.), The cognitive neurosciences (pp. 789-801). Cambridge, MA: MIT Press.

Schriefers, H., Meyer, A. S., \& Levelt, W. J. M. (1990). Exploring the time course of lexical access in language production: Picture-word interference studies. Journal of Memory and Language, 29, 86-102.

Shattuck-Huffnagel, S. (1979). Speech errors as evidence for a serial-order mechanism in sentence production. In W. E. Cooper \& E. C. T. Walker (Eds.), Sentence processing: Psycholinguistic studies presented to Merrill Garrett (pp. 295-342). Hillsdale, NJ: Erlbaum.

Shattuck-Huffnagel, S. (1983). Sublexical units and suprasegmental structure in speech production planning. In P. F. MacNeilage (Ed.), The production of speech (pp. 109-136). New York: Springer.

Shattuck-Huffnagel, S. (1987). The role of word onset consonants in speech production planning: New evidence from speech error patterns. In E. Keller \& M. Gopnik (Eds.), Motor and sensory processes of language (pp. 17-51). Hillsdale, NJ: Erlbaum.

Smid, H. G. O. M., Mulder, G., \& Mulder, L. J. M. (1987). The continuous flow model revisited: Perceptual and motor aspects. In R. Johnson, Jr., J. W. Rohrbaugh, \& R. Parasuraman (Eds.), Current trends in event-related potential research: Electroencephalography and clinical neurophysiology (Suppl. 40, pp. 270-278). Amsterdam: Elsevier.

Smid, H. G. O. M., Mulder, G., Mulder, L. J. M., \& Brands, G. J. (1992). A psychophysiological study of the use of partial information in stimulus-response translation. Journal of Experimental Psychology: Human Perception and Performance, 18 , 1101-1119.

Stemberger, J. P. (1985). An interactive activation model of language production. In W. W. Ellis (Ed.), Progress in the psychology of language (Vol. 1, pp. 143-186). Hillsdale, NJ: Erlbaum.

Vaughan, H. G., Costa, L. D., \& Ritter, W. (1968). Topography of the human motor potential. Electroencephalography and Clinical Neurophysiology, 25, 1-10.

Wheeldon, L. R., \& Levelt, W. J. M. (1995). Monitoring the time course of phonological encoding. Journal of Memory and Language, 34, 311-334.

Wohlert, A. B. (1993). Event-related brain potentials preceding speech and nonspeech oral movements of varying complexity. Journal of Speech and Hearing Research, 36, 897-905. 
Appendix A

Dutch Names and Their English Translations for the Target Pictures in Experiment 1 and Experiment 2 and Their Mean Naming and Recognition Latencies as Obtained in the Pretests

\begin{tabular}{|c|c|c|c|c|c|}
\hline \multirow{2}{*}{$\begin{array}{l}\text { Picture names grouped } \\
\text { by word-final phoneme }\end{array}$} & \multicolumn{2}{|c|}{ Reaction time (ms) } & \multirow{2}{*}{$\begin{array}{l}\text { Picture names grouped } \\
\text { by word-final phoneme }\end{array}$} & \multicolumn{2}{|c|}{ Reaction time (ms) } \\
\hline & Naming & Recognition & & Naming & Recognition \\
\hline \multicolumn{3}{|c|}{ Animals } & \multicolumn{3}{|c|}{ Objects } \\
\hline$n$ & & & $n /$ & & \\
\hline uil [owl] & 788 & 644 & tol [top] & 806 & 549 \\
\hline egel [hedgehog] & 691 & 681 & bal [ball] & 797 & 622 \\
\hline kameel [camel] & 770 & 720 & orgel [organ] & 890 & 610 \\
\hline krokodil [crocodile] & 1,059 & 632 & hengel [fishing rod] & 885 & 630 \\
\hline$/ \mathrm{s} /$ & & & $/ \mathrm{s} /$ & & \\
\hline vos [fox] & 939 & 707 & kaars [candle] & 637 & 583 \\
\hline rups [caterpillar] & 960 & 600 & vaas [vase] & 759 & 567 \\
\hline gans [goose] & 979 & 688 & muts [hat] & 810 & 604 \\
\hline muis [mouse] & 793 & 669 & ananas [pineapple] & 827 & 570 \\
\hline $\ln /$ & & & $/ n^{\prime}$ & & \\
\hline zwaan [swan] & 797 & 783 & kan [jug] & 740 & 642 \\
\hline haan [cock] & 937 & 666 & maan [moon] & 918 & 624 \\
\hline spin [spider] & 712 & 601 & kussen [pillow] & 898 & 700 \\
\hline konijn [rabbit] & 850 & 607 & ballon [balloon] & 711 & 632 \\
\hline$|r|$ & & & $|\mathrm{r}|$ & & \\
\hline beer [bear] & 976 & 616 & veer [feather] & 809 & 605 \\
\hline tijger [tiger] & 837 & 680 & deur [doar] & 638 & 587 \\
\hline kikker [frog] & 747 & 645 & spijker [nail] & 751 & 554 \\
\hline vlinder [butterfly] & 666 & 632 & motor [motorcycle] & 787 & 551 \\
\hline
\end{tabular}

Appendix B

Dutch Names and Their English Translations for the Target Pictures in Experiment 3 and Their Mean Naming and Recognition Latencies as Obtained in the Pretests

\begin{tabular}{|c|c|c|c|c|c|}
\hline \multirow{2}{*}{$\begin{array}{l}\text { Picture names grouped } \\
\text { by word-initial phoneme }\end{array}$} & \multicolumn{2}{|c|}{ Reaction time (ms) } & \multirow{2}{*}{$\begin{array}{l}\text { Picture names grouped } \\
\text { by word-initial phoneme }\end{array}$} & \multicolumn{2}{|c|}{ Reaction time (ms) } \\
\hline & Naming & Recognition & & Naming & Recognition \\
\hline \multicolumn{3}{|c|}{ Animals } & \multicolumn{3}{|c|}{ Objects } \\
\hline$/ \mathrm{k} /$ & & & k/ & & \\
\hline kameel [camel] & 770 & 720 & kanon [cannon] & 805 & 578 \\
\hline konijn [rabbit] & 850 & 607 & knoop [button] & 876 & 545 \\
\hline kuiken [chicken] & 901 & 614 & kroon [crown] & 918 & 631 \\
\hline kikker [frog] & 747 & 645 & kan [jug] & 740 & 642 \\
\hline $\mid \mathrm{s} /$ & & & $/ \mathrm{s} /$ & & \\
\hline spin [spider] & 713 & 601 & sleutel [key] & 686 & 574 \\
\hline schaap [sheep] & 845 & 697 & schoen [shoe] & 608 & 578 \\
\hline stier [bull] & 1,045 & 649 & sigaar [cigar] & 814 & 641 \\
\hline slang [snake] & - & - & schaats [skate] & 674 & 620 \\
\hline$/ \mathrm{v} /$ & & & $/ \mathrm{v} f$ & & \\
\hline varken [pig] & 892 & 609 & veer [feather] & 809 & 605 \\
\hline vlinder [butterfly] & 666 & 631 & vaas [vase] & 759 & 567 \\
\hline $\operatorname{vos}[$ fox $]$ & 938 & 707 & vlag [flag] & - & - \\
\hline vis [fish] & - & - & vork [fork] & - & - \\
\hline$/ \mathrm{h} /$ & & & $/ \mathrm{h} /$ & & \\
\hline haan [cock] & 936 & 666 & harp [harp] & 751 & 603 \\
\hline hert [deer] & 875 & 660 & hengel [fishing rod] & 885 & 630 \\
\hline hond [dog] & 658 & 696 & hamer [hammer] & 740 & 640 \\
\hline hagedis [lizard] & - & - & hoefijzer [horseshoe] & 846 & 573 \\
\hline
\end{tabular}

Note. Dashes indicate pictures that were not included in the pretests. These pictures were selected on the basis of naming responses and response latencies obtained in other pretests carried out at the Max Planck Institute. 